\title{
LOS ESTUDIANTES SECUNDARIOS DURANTE LA UNIDAD POPULAR, 1970-1973**
}

\begin{abstract}
RESUMEN
Este estudio busca reconstruir la experiencia organizativa y la participación política de los estudiantes secundarios en el conflictivo período en que gobernó Salvador Allende (1970-1973). Desde el entusiasmo inicial hasta las profundas fisuras que dividieron en dos bloques a la Federación de Estudiantes Secundarios de Santiago (FESES), el período estuvo dominado por un alto nivel de politización y una participación masiva de los estudiantes, que pocas veces se había observado y que tardaría en repetirse. Aunque el tema educacional fue uno más de los frentes de lucha de los actores sociales y políticos de la época, en él quedaron en evidencia las distintas posturas en juego y la forma en que se estructuró la acción partidaria.
\end{abstract}

Palabras clave: Unidad Popular, movimiento estudiantil, juventud, Escuela Nacional Unificada.

\begin{abstract}
This study reconstructs the organizing experience and political participation of High School students during the conflictive period in which Salvador Allende governed Chile (1970-1973). From an initial enthusiasm to the appearance of deep cracks that divided the Federación de Estudiantes Secundarios (FESES) in two blocs, the period was characterized by a high level of politicization and a massive student participation, few times seen, which took longer to reappear in Chile. Although education was only one of the various struggle fronts that motivated social and political actors of that time to participate, it is possible to see here evidences of the main political stances and partisan structure of Chile.
\end{abstract}

Key words: Popular Unity, Student Movement, Youth, Unified National School.

Fecha de recepción: marzo de 2009

Fecha de aceptación: julio de 2009

* Magíster en Ciencias Sociales. Universidad Alberto Hurtado, Universidad ARCIS. Correo electrónico: jorgerojasflores@ hotmail.com

** Este artículo es uno de los resultados del proyecto Fondecyt Regular $N^{\circ} 1071033$, del cual el autor es investigador responsable. 


\section{INTRODUCCIÓN}

Los estudios sobre la juventud usualmente han dejado de lado la tradición organizativa de los estudiantes secundarios, situándose en forma preferente en torno a las acciones desplegadas por los universitarios. En parte, esto se debe a que, comparativamente, el movimiento de los "secundarios" (como se los denomina generalmente) ha sido más débil, menos estructurado, más dependiente de otros sujetos sociales y más inestable a lo largo del tiempo. Sin embargo, en determinadas coyunturas, la situación ha sido muy distinta, adquiriendo una notable fuerza y protagonismo.

Estudios recientes han reconstruido algunas de estas coyunturas, como fue el proceso de gestación de la Federación de Estudiantes Secundarios de Santiago (FESES) en la década de los 40; la refundación de esta a fines de los 80, en un contexto de dictadura; y las últimas movilizaciones, el "Mochilazo" de 2001 y la "Revolución de los Pingüinos" de 2006 '.

La inexistencia de una investigación que ofrezca una síntesis más completa limita las posibilidades de ofrecer un marco general para el presente artículo, que se sitúa en torno a la actuación de los estudiantes secundarios durante la experiencia de la Unidad Popular (UP), entre 1970 y 1973. Sabemos que su presencia en las calles se hizo característica en los años 60 . A diferencia de sus ocasionales apariciones durante la década del 50, en los años siguientes se hicieron habituales las marchas, los incidentes con la policía y las demandas en diversas materias: protestas contra la política económica (la desnacionalización del petróleo, junio de 1959) y la política educacional (mayo de 1960, agosto de 1962, septiembre de 1966), en solidaridad con estudiantes procesados (agosto de 1967) y trabajadores en huelga (julio de 1965, abril-mayo de 1968, agosto de 1968); contra el intervencionismo norteamericano (junio de 1969), el servicio militar (abril de 1969) y el alza de pasajes de la locomoción colectiva (22 de abril de 1965). En buena parte de la década de 1960 era evidente su presencia en las calles, tanto por motivaciones sectoriales como nacionales.

Lo novedoso de la movilización de los secundarios durante la Unidad Popular fue que esta se masificó, alcanzó un nivel de relevancia política como nunca había tenido, tuvo mayor continuidad y rebasó los límites de la izquierda. Esto se expresó, entre otros aspectos, en la aparición de nuevas organizaciones y nuevos liderazgos.

\section{LAS ORGANIZACIONES}

En términos orgánicos, los estudiantes secundarios de los establecimientos fiscales estaban agrupados en distintas instituciones, de carácter nacional y zonal, desde comienzos de los años 40. Ya por entonces era visible la participación de las más

1 Jorge Rojas Flores, "Las organizaciones estudiantiles", en Moral y prácticas cívicas en los niños chilenos, 1880-1950, Santiago, Ariadna Ediciones, 2004, 283-360; Rolando Álvarez, "Las Juventudes Comunistas de Chile y el Movimiento Estudiantil Secundario: Un caso de radicalización política de masas (1983-1988)", en Alternativa 23, Santiago, 2005, 83-114; Andrea Domedel y Macarena Peña y Lillo, El Mayo de los Pingüinos, Santiago, Ediciones Radio Universidad de Chile, 2008. 
diversas corrientes políticas en su interior: radicales, socialistas, comunistas, falangistas, social-cristianos y conservadores ${ }^{2}$. La Federación de Estudiantes Secundarios de Santiago, nacida a fines de 1948, era la de mayor significación política. Durante los años 60 y al asumir Allende, la izquierda predominaba en su dirección casi sin contrapeso. En las restantes ciudades, las federaciones provinciales no alcanzaron el mismo nivel de presencia en la prensa, pero su papel era importante a nivel local. En ellas había más equilibrio político, ya que también existían federaciones controladas por la Democracia Cristiana (DC), teniendo la izquierda mayor presencia en las ciudades más grandes ${ }^{3}$. A diferencia de la situación imperante en Santiago, las restantes federaciones provinciales no hacían mayor diferencia entre los liceos fiscales y particulares, o entre humanistas y técnicos, lo que también favoreció una mayor presencia de estudiantes de extracción social media y alta ${ }^{4}$.

Estas federaciones estaban agrupadas, a nivel nacional, en la Federación de Estudiantes Secundarios de Chile (denominada FES, FESCh o bien FESECh), que existía al menos desde 1945, aunque su estructura impedía que tuviera gran presencia y capacidad de movilización, salvo cuando las delegaciones se reunían, anualmente, para elegir la directiva. En los años 60, la participación de las federaciones provinciales -donde la Democracia Cristiana tenía mayor control-contrapesaba la influencia de la FESES, que estaba en poder de la izquierda. Esta última, en minoría, menospreciaba el papel que cumplía la federación nacional. En 1971, por ejemplo, un dirigente comunista de la FESES afirmaba que la FESECh solo representaba a una décima parte del estudiantado del país ${ }^{5}$. En la prensa de derecha se coincidía en que la FESECh no tenía mayor significación práctica ${ }^{6}$.

Pero esta débil representatividad, de ser cierta, no parece haber sido un problema exclusivo de la FESECh, ya que la propia FESES mostraba síntomas similares. $\mathrm{Su}$ estructura estaba basada en un sistema indirecto de representación, que se traducía en la elección de delegados, quienes se reunían anualmente para la elección de la directiva. Los liceos que participaban regularmente en la FESES no pasaban

2 Las organizaciones anteriores a 1945 no parecen haber tenido continuidad. Sobre los diversos intentos de organización a nivel nacional y provincial, véase Rojas Flores, op. cit., 283-360.

3 No tenemos un listado detallado de las federaciones provinciales, pero tenemos referencias de su existencia en Arica (Federación de Estudiantes Medios de Arica, FEMA), Antofagasta (Federación Comunal Estudiantil de Antofagasta, FECEA), San Felipe (Federación de Estudiantes Medios de San Felipe, FEMSEP), Ovalle (Federación de Estudiantes Medios de Ovalle, FEDEMO), Valparaíso (Federación de Estudiantes Secundarios de Valparaíso), Curicó (Federación de Estudiantes Secundarios de Curicó), Biobío (Federación de Estudiantes Secundarios del Biobío, FESEB), Concepción (Federación Provincial de Estudiantes Secundarios de Concepción, FEPRESCO), Angol (Federación de Estudiantes de Angol, FEDA), Osorno (Federación de Estudiantes Medios de Osorno, FESMO), Chillán (Federación de Estudiantes de Chillán) y Magallanes (Federaciones de Estudiantes de Educación Media de Magallanes). Un listado de las federaciones proclives a la DC en La Prensa, Santiago, 4 de septiembre de 1972, 13. Otras referencias con ocasión de las movilizaciones de abril de 1973, en El Mercurio, Santiago, 25 y 26 de abril de 1973, y La Prensa, 11 de abril de 1973, 17. El triunfo de la oposición en la FECEA, en Tribuna, Santiago, 10 de noviembre de 1972, 16.

4 En Curicó, por ejemplo, en 1973 el presidente de la federación era Aldo Cornejo, estudiante de los Hermanos Maristas. El Mercurio, 26 de abril de 1973, 25.

5 "Álvaro Alarcón, candidato a FESES. Integraremos aun más al estudiantado a las tareas de nuestra revolución”, en El Siglo, Santiago, 5 de octubre de 1971, 1.

6 "El último decreto de Aníbal Palma", en Qué Pasa 82, Santiago, 9 de noviembre de 1972, 13. 
de una veintena, en particular aquellos con mayor tradición organizativa, lo que provocaba una clara "sobrerrepresentación" de la izquierda. Adicionalmente, la rivalidad entre comunistas y socialistas alcanzaba niveles bastante tensos, que podían traducirse en pugilatos y enfrentamientos callejeros ${ }^{7}$.

Paralelamente, el Estado venía promoviendo la organización de centros de alumnos, dictando incluso una normativa al respecto en $1949^{8}$, que fue sustituida por el Gobierno, a principios de 1970, por otra que demostró ser bastante más respetuosa hacia las organizaciones estudiantiles, en comparación con la vigente hasta entonces. En el nuevo reglamento se planteó que los centros de alumnos tenían por función servir a sus miembros, para desarrollar en ellos "el pensamiento reflexivo, el juicio crítico y la voluntad de acción", "formarlos para la vida democrática" y prepararlos en los cambios culturales y sociales. Una novedad del texto fue que el Estado aceptó la idea de que el centro de alumnos designara sus representantes ante organizaciones estudiantiles con las cuales tuviera relaciones ${ }^{9}$.

Las federaciones estudiantiles provinciales y nacionales seguían existiendo de hecho, sin un reconocimiento legal que tampoco buscaban. Al parecer, el reconocimiento formal se limitaba a los centros de alumnos, que funcionaban a nivel de los establecimientos.

En noviembre de 1969 la FESES se había quebrado. La circunstancia particular fue la pugna en la aprobación de poderes de los delegados a la convención, donde, como todos los años, se nominaba a la directiva. A consecuencia de ello, un sector quedó dominado por los socialistas (junto al MIR y el MAPU) y otro por los comunistas. Los democratacristianos, en minoría, se excluyeron de este conflicto y retiraron a sus dirigentes del ejecutivo. Ya por entonces, los grupos que se disputaban la FESES se mostraban favorables a la elección directa, pero faltaba un par de años para que esto se produjera ${ }^{10}$.

7 Silvia recuerda uno de esos tantos enfrentamientos, a fines de la década de los 60, en pleno centro de Santiago, que terminó cuando uno de los estudiantes cayó y se fracturó gravemente. Se produjo un extraño alto en la refriega y el muchacho fue llevado a un centro médico. Testimonio de Silvia Fernández al autor, 15 de febrero de 2008.

8 Decreto 5.969, del Ministerio de Educación Pública, 30 de junio de 1949, publicado el 23 de septiembre de 1949. Rojas Flores, op. cit., 355-356.

9 Decreto 558, del Ministerio de Educación, 23 de enero de 1970, publicado el 17 de febrero de 1970 .

10 La XXI Convención de la FESES se realizó entre el 31 de octubre (viernes) y el 2 de noviembre de 1969 (domingo). La pugna por las credenciales se desató el sábado, momento en que ambos grupos sesionaron en forma separada. Las versiones oficiales de ambos bandos difieren notablemente, lo que se reflejó en la prensa. Las descalificaciones de divisionismo a través de la prensa fueron muy ácidas. "Momios, miristas y nazis intentan quebrar la FESES", en El Siglo, 2 de noviembre de 1969, 9; "Dice dirigente de la FESES: Los divisionistas han sido rechazados", en El Siglo, 4 de noviembre de 1969, 9; "Categórico desmentido: Convención de secundarios no logró ser dividida", en El Siglo, 5 de noviembre de 1969, 6; "Carta de la Juventud Socialista a las juventudes Comunistas", en El Siglo, 13 de noviembre de 1969, 6. Para el detalle de ambas versiones: "Con su guapa rosca terminó Convención de secundarios", en Clarín, Santiago, 3 de noviembre de 1969, 10; "Cabros secundarios aclaran sus dichos", en Clarín, 4 de noviembre de 1969, 10; “Quedó 'chuchoca' entre estudiantes secundarios", en Clarín, 5 de noviembre de 1969, 10. Referencias posteriores al quiebre y sus consecuencias en "Elecciones son el próximo jueves. La DC secundaria luchará por una Federación al servicio de los alumnos", en La Prensa, 25 de septiembre de 1971, 7; y "Significado de una elección estudiantil" (edit.), en La Prensa, 10 de octubre de 1971, 3. 
Los estudiantes secundarios que pertenecían a la educación fiscal técnica, industrial y especial estaban agrupados, a nivel nacional, en una organización distinta, denominada Federación de Estudiantes Industriales, Técnicos y Especiales (al parecer, bajo la sigla FEITECh), que contaba con una rama local en Santiago (FEITES), ambas de orientación izquierdista y creadas probablemente en $1960^{11}$. A la FEITECh se le atribuía una representación de 80 a 120 mil estudiantes en todo el país ${ }^{12}$. Los liceos comerciales tenían otra organización, la Federación de Estudiantes de Comerciales o FECOCh, también controlada por la izquierda ${ }^{13}$. Los vínculos de ambas federaciones con la FESES (hasta 1971) eran estrechos, debido a su afinidad política y su similar composición social. Sin embargo, su presencia en la prensa era escasa y tenemos menos referencias sobre su capacidad de movilización durante el período.

Al parecer, los estudiantes de colegios particulares no llegaron a organizarse a nivel nacional ni provincial, hasta que las circunstancias creadas por la Unidad Popular lo hicieron posible. Las demandas del sector privado hacia el Estado eran canalizadas solo a través de las organizaciones que representaban a las instituciones que eran propietarias de los establecimientos, como la Iglesia o algunas fundaciones privadas ${ }^{14}$.

\section{EL TRIUNFO DE ALLENDE}

Las federaciones estudiantiles que tenían una visible orientación izquierdista -como la FESES y la FEITECh/FEITES- participaron con entusiasmo de la llegada al poder de la Unidad Popular. No solo se sumaron al ambiente de fiesta que rodeó el triunfo mismo, sino que rápidamente se incorporaron a los trabajos voluntarios, desde noviembre de 1970, con la tarea explícita de participar en la construcción de plazas de juegos infantiles. Así lo acordaron en una asamblea de dirigentes de las federaciones de enseñanza media. En estas primeras marchas, en pleno verano, los gritos de la muchachada eran festivos y chispeantes (“¡uf uf qué calor, un guanaco por favor!"), pero también cargados de compromiso político con el proceso que se iniciaba (“¡Estudiantes con obreros, construiremos un Chile nuevo!”) ${ }^{15}$.

11 La nueva directiva elegida a fines de 1971 estaba presidida por Víctor Hugo Ruiz (socialista), como presidente, y Moisés Magallanes (comunista), como secretario general. "En XII Congreso de FEITES. Participación de escuelas en el proceso de desarrollo del país", en El Siglo, 17 de octubre de 1971, 6. Las primeras organizaciones estudiantiles de los liceos técnicos se remontan a 1935, año de fundación de la FEST. Véase Rojas Flores, op. cit., 315-318.

12 La primera cifra aparece en Mayoría 14, Santiago, 19 de enero de 1972, 25, donde se indica además que, de ese total, unos 25 mil eran de Santiago. La segunda cifra la menciona Ricardo Solari en El Siglo, 28 de septiembre de 1972, 7.

13 Las escasas noticias de la FECOCh las debemos a la información que entrega Ricardo Solari en El Siglo, 28 de septiembre de 1972, 7.

14 La de mayor prestigio y tradición era la Federación de Instituciones de Educación Particular, FIDE, creada en 1948, que en la época de la Unidad Popular estaba segmentada según el nivel de enseñanza: FIDE Primaria, FIDE Secundaria, etc.

15 "Estudiantes de Enseñanza Media: Contingente firme para construir y alfabetizar", en El Siglo, 29 de noviembre de 1970, 13; "Pacífica concentración y desfile: Secundarios fueron a ofrecer esfuerzo y sacrificio a la Moneda", en El Siglo, 28 de noviembre de 1970, 5. 
Hubo jóvenes de extracción católica, como Osvaldo Artaza, por entonces de 15 años, que aun siendo partidarios de Tomic salieron a celebrar el 4 de septiembre de 1970. Su tendencia política, por entonces, era claramente de izquierda. Apenas con 13 años, por ejemplo, Osvaldo había participado en la toma de la Catedral, organizada por un grupo de cristianos favorables al socialismo. Por iniciativa de los jesuitas, entre los que se destacaba Emilio ("Gato") Vergara, varios estudiantes de colegios católicos participaban por entonces en un grupo de reflexión y luego de acción política, que se reunían en calle Riquelme 80. Allí confluyeron varios dirigentes que luego seguirían caminos divergentes, con militancias en la DC (Osvaldo Artaza), el MAPU (Francisco Estévez, Jorge Marshall) e incluso el MIR. Por entonces, todos parecían compartir un espíritu a favor de la democratización y el cambio social profundo. De ahí su entusiasmo por el triunfo de Allende ${ }^{16}$.

Fue este grupo el que estuvo detrás de la unificación de los estudiantes de colegios particulares. En septiembre de 1971 se anunció públicamente que una veintena de establecimientos había constituido la Federación Única de Estudiantes de Colegios Particulares (FUEP). En sus primeras declaraciones, según la prensa, defendió la autonomía de la educación privada, rechazó los intentos de estatización y criticó el concepto "clasista" de la educación particular, es decir, la existencia de una educación privilegiada para la élite. Según se publicó por entonces, gran parte de los colegios reunidos en la FUEP eran gratuitos. Su primer presidente fue José Miguel Crispi, un estudiante de 16 años ${ }^{17}$.

Osvaldo Artaza era estudiante del Colegio San Ignacio y compañero de curso de Crispi. Aunque había apoyado la candidatura de Tomic (mientras Crispi se había inclinado por Allende), ambos representaban posiciones de izquierda. La FUEP misma todavía tenía una postura más bien de simpatía por el proceso. Artaza, en su calidad de dirigente estudiantil, participó en 1971 en uno de los tantos congresos para discutir el proyecto educacional y sintió afinidad con todas las propuestas de cogestión, democratización y cambios en la educación pública y privada ${ }^{18}$.

Mercedes, por entonces alumna de un colegio católico particular subvencionado, participó en algunas reuniones donde se discutió su ingreso a la FUEP. Según recuerda, los grupos de izquierda de esta federación invitaban a los colegios particulares pobres, como el suyo, para así por poder contrapesar a los grupos de derecha que tenían presencia en la FUEP. Entre ellos había algunos líderes como Andrés Allamand, por entonces estudiante del Saint George ${ }^{19}$. Artaza, en cambio, tiene una imagen más bien homogénea de esta federación, por lo menos en cuanto a sus dirigentes principales, quienes provenían de colegios pagados: varios del San Ignacio; Elena Téllez, de las Teresianas; Emilio Santelices, del Hispano Americano, otros del Liceo Alemán, etc. ${ }^{20}$.

16 Testimonio de Osvaldo Artaza al autor, 19 de mayo de 2009.

17 "Estudiantes de colegios particulares crearon su propia federación", en La Prensa, 19 de septiembre de 1971, 6. José Miguel Crispi es padre de Miguel Crispi (JS), elegido presidente de la FEUC a fines de 2008 .

18 Osvaldo Artaza, cit.

19 Testimonio de Mercedes Gallegos al autor, 19 de mayo de 2009.

20 Osvaldo Artaza, cit. 
De un modo todavía invisible, en otros sectores de estudiantes el triunfo de la Unidad Popular provocó espanto, desconcierto y temor, como si una catástrofe de proporciones se hubiera impuesto sobre el país: la amenaza de una dictadura comunista o bien el alzamiento del populacho ${ }^{21}$. Los estudiantes de derecha que no se sentían representados por la FESES y, por lo mismo, se habían excluido de ella, sintieron un fuerte impulso por organizarse. Andrés Allamand recuerda el impacto político que vivió la noche del 4 de septiembre de 1970. En esta primera fase, comenzó a integrarse al trabajo de la naciente FUEP, aunque sin compartir el enfoque de la directiva ${ }^{22}$.

\section{LA ELECCIÓN DIRECTA EN LA FESES (1971)}

Mientras se gestaba la unidad entre los colegios particulares, la FESES continuaba dividida, con dos directivas de izquierda, aunque con una estrategia definida para revertir esta situación. Es muy probable que la imperiosa necesidad de mantener una mayor armonía en favor de la Unidad Popular haya contribuido a que esta decisión se impusiera. Como se había acordado en 1969, el mecanismo elegido fue la realización de una elección directa, con base en un procedimiento que otorgaba el poder directo a los estudiantes de cada establecimiento, sin la intermediación de delegados. Adicionalmente, se propuso ampliar la base electoral, incorporando a la totalidad de los liceos fiscales de la provincia. El procedimiento de consultas aumentó la base de la FESES a más de cincuenta establecimientos. En vísperas de la elección, de ese total de liceos, la DC controlaba 12 centros de alumnos y la derecha no tenía mayor presencia ${ }^{23}$. Por primera vez pudieron votar directamente unos 70 mil estudiantes. Esta oleada de participación, en su acepción más amplia y directa, fue algo característico del período de la Unidad Popular y provocó un efecto indirecto: un mayor espacio de participación para la oposición ${ }^{24}$.

21 Aunque fuera del ámbito de la juventud, quizás el relato más claro al respecto lo ofrece Hernán Díaz Arrieta (Alone), en una carta fechada el 15 de octubre de 1970: "Hace ya más de un mes que vivimos una novela de suspenso, un día temiendo lo peor, otro día con leves esperanzas, las justas para que al día siguiente se renueve la pesadilla. Siento como si hubiera cambiado todo, hasta la cordillera, me siento en Chile como extranjero de un país hostil, rodeado de asechanzas y peligros [...]. Todos los que podían han escapado ya de la catástrofe y los que permanecen forzados están enfermos y no se oyen sino lamentaciones siniestras. Se ha producido ya la sublevación de los espíritus, si es que el populacho lo tiene, y no se puede confiar en nadie ni en nada [...] Yo he perdido completamente la fe en la libertad y, entonces, ¿para qué, por qué combatir? Pensar que con el muro de Berlín a la vista, con el aplastamiento de Checoslovaquia en perspectiva y a pesar del discurso de Fidel Castro, la mayoría ha votado por el comunismo, constituye un tal certificado de estupidez nacional que la palabra patria ya no tiene sentido, es otro mundo, otra atmósfera. La hora más terrible es la del despertar y volver a convencerse de que somos un país comunista, que habrá que someterse, resignarse y adaptarse al más aborrecido de los regímenes, a una especie de cárcel". Alejandrina Carey C. et al., Chile: Cartas con historia, Santiago, Editorial Los Andes, 1998, 128-129.

22 “Andrés Allamand. De la mano con la razón”, en Qué Pasa 104, 12 de abril de 1973, 18-19.

23 La referencia a los centros de alumnos controlados por la DC aparece mencionada un año después. Véase "Mayoría DC en los liceos", en La Prensa, 14 de noviembre de 1972, 9.

24 Esto se reflejó no solo en la FESES, sino también en la CUT y el SUTE, donde la oposición ganó terreno tras las elecciones directas que se organizaron. 
El clima político de esta elección no fue el de cualquier acto electoral. Convocada para fines de 1971, puso al rojo vivo la disputa entre las distintas agrupaciones políticas. La incorporación de nuevos liceos rompió el escenario previsible que hasta entonces había predominado: por ejemplo, aumentaron los liceos de niñas y se agregaron liceos de barrios más acomodados, lo que abrió las posibilidades para que un abanico más amplio de posiciones políticas quedaran representadas. Adicionalmente, surgieron muchas críticas hacia la conducción de la FESES (por entonces en manos de la izquierda), en especial por su exceso de politización, críticas que fueron canalizadas por la candidatura de la DC.

A la elección se presentaron cinco listas: una que agrupaba a los partidos de la UP, es decir, el Partido Socialista, el PC y el MAPU, apoyada también por la Izquierda Cristiana (IC); otra integrada por el Frente de Estudiantes Revolucionarios (FER, mirista) y la Juventud Radical Revolucionaria (JRR); una lista de derecha, que aglutinaba al Partido Nacional (PN) y la Democracia Radical (DR), además de Patria y Libertad; una de la DC, que postuló en forma separada; y finalmente una quinta lista que lideraban representantes de los radicales más moderados (de Luis Bossay, integrados en el Movimiento Radical Independiente; además de los socialdemócratas).

Inicialmente, la lista de la UP no acordó un candidato a la presidencia, debido a que socialistas y comunistas preferían que la propia elección dirimiera quién tenía mejor opción. Probablemente, todavía sobrevivían los viejos resquemores entre ambos sectores ${ }^{25}$. Pero finalmente se acordó que la lista incorporara a un candidato a la presidencia y el nombre elegido fue Álvaro Alarcón, ex presidente de la FESES y militante comunista; secundado por el socialista Rigoberto (Rigo) Quezada. Ambos eran "veteranos" estudiantes secundarios. Dentro de la lista, al parecer la más joven era Lina Rivas, presidenta del centro de alumnas del Liceo 7 de Niñas, de 15 años.

Los democratacristianos no tuvieron duda en el liderazgo de Guillermo Yunge. $\mathrm{Su}$ figura no era desconocida, ya que desde mediados de los 60 venía incursionando en el movimiento estudiantil, a pesar de su corta edad. En las movilizaciones de aquella época, aunque era alumno del Liceo 12 de Conchalí, era habitual verlo en el Liceo Amunátegui, como lo recuerda Silvia, una de las tantas alumnas del Liceo 2 que lo adoptó como "mascota" 26.

En la lista conjunta de miristas y radicales oficialistas, se presentó la candidatura de Milton Lee. La lista de la derecha, integrada por la Juventud Nacional (JN) y la Democracia Radical, estaba liderada por Carlos Perelló. Finalmente, los radicales moderados (MRI y socialdemócratas) llevaron como candidato a Alberto $\mathrm{Cuno}^{27}$.

25 "Postergan la elección: JDC secundaria impuso sus posiciones ante candidatos oficialistas", en La Prensa, 30 de octubre de 1971, 5.

26 Silvia Fernández, cit. Yunge había nacido en septiembre de 1953.

27 El Siglo, 4 de octubre de 1971, 5. Sobre las candidaturas y el clima electoral, "Los secundarios", en Qué Pasa 25, 7 de octubre de 1971, 11-12. 
Para cambiar la composición de fuerzas políticas en la FESES, cada cual buscó el mejor escenario. Por ejemplo, la oposición hizo esfuerzos por integrar a los colegios particulares a la Federación, algo reñido con sus estatutos. Ante el fracaso de esta estrategia, se volcaron a aumentar la presencia de los liceos fiscales, en donde la izquierda tenía menos fuerza. La UP, por su parte, se preocupó de acelerar el mecanismo para aceptar las postulaciones de algunos establecimientos nuevos donde tenía fuerte presencia, uno de los cuales fue el Liceo Che Guevara, transformado en Liceo 26.

En esta pugna desatada por motivos electorales, uno de los temas en conflicto fue la exclusión de los liceos 11 y 14 de Las Condes. A raíz de esto, un grupo de estudiantes de derecha (en su mayoría hombres) se tomó el Liceo 7 de Niñas de Providencia en vísperas de la elección, además del Liceo Lastarria. La oposición denunció, además, la intervención gubernamental y de universitarios en la campaña ${ }^{28}$.

El acto electoral, realizado finalmente el 6 de octubre de 1971, se llevó a cabo en un clima tenso, pero donde predominó una relativa normalidad (interrumpida solo por las dos tomas mencionadas). Sorpresivamente, los resultados favorecieron a la DC, cuya lista obtuvo un 41,6\% de los votos, seguida por la UP que concentró un $36,7 \%$. De la directiva de la FESES, compuesta por 15 miembros, diez quedaron en manos de la DC (entre ellos, los cinco del secretariado ejecutivo), cuatro de la UP (entre estos, un comunista) y uno del FER (mirista).

\section{RESULTADOS OFICIALES DE LA ELECCIÓN DE LA FESES, 1971}

\begin{tabular}{lcc}
\hline Listas & Votos & $\%$ \\
\hline UP & 13.287 & 36,7 \\
DC & 15.050 & 41,6 \\
FER-JRR & 3.088 & 8,5 \\
JR Independ-SD & 180 & 0,5 \\
JN-DR & 2.826 & 7,8 \\
Blancos & 200 & 0,6 \\
Nulos & 1.581 & 4,4 \\
& 36.212 & 100,1 \\
\hline
\end{tabular}

Fuente: TRICEL, publicados en La Prensa, 9 de octubre de 1971.

Al interior de la UP se produjo un fuerte remezón político, del que dio cuenta el diario El Siglo. En su opinión, la falta de unidad en la izquierda había sido uno de los factores decisivos del fracaso (esto debido a que las dos listas de izquierda sumaban más que la lista triunfante de la DC), además de la alta proporción de estudiantes con "menor conciencia política" que se habían incorporado a la elec-

28 Al respecto, véase La Prensa, a fines de septiembre y comienzos de octubre de 1971, y "Los secundarios", op. cit. 
ción ${ }^{29}$. Ante estos resultados, los comunistas llamaron a cerrar filas contra el peligro fascista, representado por Patria y Libertad y el Partido Nacional. Esto significaba tender puentes hacia la directiva democratacristiana. Al interior de la UP, el mayor apoyo electoral logrado por los socialistas por sobre los comunistas tuvo efecto directo en la elección de la FESES del año siguiente ${ }^{30}$.

Los democratacristianos dieron gran realce a los resultados, que interpretaron como un ejemplo del aislamiento en que se encontraba la UP y de la capacidad que tenían los jóvenes (del más variado origen social) para liderar un proceso de lucha por la libertad y la democracia, contra la manipulación y el "totalitarismo marxista". La izquierda no podía siquiera esgrimir un "contubernio" con la derecha, ya que esta había ido en lista separada ${ }^{31}$. El fracaso DC entre los universitarios parecía verse compensado con este éxito entre los secundarios ${ }^{32}$. Incluso, la DC le atribuyó más importancia a esta victoria que al reciente triunfo parlamentario en una elección complementaria por Valparaíso, ya que era una demostración de la vitalidad de la JDC $^{33}$.

\section{YUNGE, PRESIDENTE DE LA FESES}

La directiva de la FESES encabezada por Yunge sentó las bases del nuevo protagonismo de los secundarios. Un hecho simbólico de la nueva etapa fue el traslado a su nueva sede, en calle Fanor Velasco, al parecer cedida por la Democracia Cristiana. Hasta entonces, la FESES había funcionado en varios locales, el último bajo el alero de la FECh, en Alameda con Santa Rosa.

Durante los últimos meses de 1971, la postura de la FESES no fue claramente opositora al Gobierno. Por ejemplo, a raíz de los problemas con EE.UU. en las

29 Según los cálculos del PC, la UP había ganado en los liceos con mayor tradición de organización estudiantil (liceos 1 y 2 de hombres) y con mayor extracción popular (Escuela Consolidada Dávila), y había perdido en los liceos recién integrados a la FESES (liceos 1 y 3 de niñas). Eduardo Carrasco, "Resultado de la FESES preocupa a la Unidad Popular" y "JJCC frente a elección de FESES: Desarrollar a la ofensiva, un mayor trabajo de masas", en El Siglo, 9 de octubre de 1971, 2 y 3. En la prensa de oposición se destacaba lo contrario: la oposición había reforzado posiciones en los establecimientos con mayor tradición de izquierda (como el Liceo 6 de hombres, de San Miguel). "Elección Feses", en La Prensa, 7 de octubre de 1971, 5.

30 El PS enrostró al PC el que un dirigente de sus filas hubiera encabezado la lista de la UP. Según sus cálculos, los socialistas habían aportado más del $60 \%$ de los votos a la lista. Véase "JS analiza elecciones de FESES”, en El Siglo, 10 de octubre de 1971, 9. En la elección de 1972, un socialista (Camilo Escalona) postuló a la presidencia en representación de la Unidad Popular.

31 "Un triunfo de proyecciones" (edit.), en La Prensa, 8 de octubre de 1971, 1; "Significado de una elección estudiantil”, op. cit.

32 Recordemos que la DC había liderado la FECh desde 1964 hasta 1968. En 1969 perdió frente a la lista de la UP, tendencia que se mantuvo hasta el final del gobierno de Allende. En la FESES, el predominio de la izquierda desde los años 50 se revirtió en 1971, con el triunfo de la DC. Sin embargo, en este balance general no se consideran las alianzas o divisiones en las listas.

33 El triunfo parlamentario correspondió al doctor Óscar Marín. El fracaso del "divisionismo" de la IC (recién escindida de la Democracia Cristiana) quedó representado en la figura de Luis Badilla, ex presidente de la JDC, quien no pudo integrar dirigentes secundarios de la Izquierda Cristiana al directorio de la FESES. Al respecto, véase "Opinan parlamentarios: Triunfo de secundarios DC es más importante que el obtenido en Valparaíso”, en La Prensa, 8 de octubre de 1971, 1. 
negociaciones por la Nacionalización del Cobre, la Federación apoyó con entusiasmo las movilizaciones antinorteamericanas. Valorando la política del Gobierno y de "amplios sectores progresistas, que están por la construcción de una Nueva Sociedad”, declaró "su total y combativo apoyo a la Nacionalización”, lo que significaba estar alerta a las movilizaciones. La JDC había mostrado similar confluencia con la izquierda, por lo que no debe sorprender esta posición de la FESES $^{34}$.

En todo caso, esta postura no era aceptada por todos los secundarios. En el Liceo 11 de Las Condes, donde eran más fuertes los grupos de ultraderecha, la política del cobre no era un punto de encuentro con la Unidad Popular. En ese liceo hubo protestas por una exposición gubernamental sobre la Nacionalización del Cobre: el Centro de Alumnos se opuso a su instalación y un pugilato acompañó la visita de los periodistas del Canal 9 de la Universidad de Chile, quienes fueron a reportear lo sucedido ${ }^{35}$.

Frente al triunfo de la FESES, las Juventudes Comunistas adoptaron una postura oficialmente cautelosa. Valoraron, por ejemplo, el apoyo de la JDC a la campaña en favor de la Nacionalización, pero también se encargaron de recordar que la izquierda controlaba la mayor parte de los centros de alumnos (un 75\%) y que no permitirían que la FESES se convirtiera en un instrumento contra el Gobierno ${ }^{36}$. El ambiente en general era más bien de rivalidad. En el acto "unitario" en torno al tema de la Nacionalización predominaron los roces y los enfrentamientos, y finalmente Yunge no pudo hacer uso de la palabra ${ }^{37}$.

Tampoco los grupos cercanos a la UP dieron su apoyo a las movilizaciones convocadas por la directiva de la FESES por demandas "gremiales". Esta fase de movilización se inició a fines de noviembre de 1971 y el motivo directo fueron ciertos cambios administrativos que afectaron el sistema de promoción del alumnado secundario ${ }^{38}$.

Otra zona de conflicto que se desarrolló a fines de 1971 fue la polémica en torno a los encuentros organizados para debatir la situación educacional y la próxima reforma. En ellos podían participar delegaciones de varios sectores (padres, profesores, trabajadores, etc., además de los propios estudiantes), pero el número de representantes fue objeto de pugnas, así como el registro del debate,

34 "Declaración de Yunge: FESES en estado de alerta contra ataques yanquis", en El Siglo, 20 de octubre de 1971, 3 .

35 "Dos funcionarios de Enami protagonizaron incidentes en Liceo", en La Prensa, 10 de noviembre de 1971,5 .

36 "Juventudes Comunistas llaman a movilizarse contra amenaza yanqui", en El Siglo, 16 de octubre de $1971,3$.

37 "Aún pena la derrota: FESES aclara falsas acusaciones hechas por la Unidad Popular", en $L a$ Prensa, 11 de diciembre de 1971, 7.

38 El objeto particular de la disputa fue el Decreto 2.715, del Ministerio de Educación, que estableció normas sobre evaluación y promoción de alumnos. "Solucionado problema de estudiantes secundarios", en El Siglo, 24 de noviembre de 1971, 9; "Se concentrarán a las 11 horas. Ni estudiantes oficialistas están de acuerdo con la política educacional de UP”, en La Prensa, 23 de noviembre de 1971, 5. Sobre el rechazo a estas demandas "gremiales", véase "Aún pena la derrota: FESES aclara falsas acusaciones hechas por la Unidad Popular", op. cit. 
que no siempre consideraba el voto de minoría. Hubo varias denuncias por sectarismo e intolerancia, además de la polémica misma sobre el carácter de la reforma. En algunos congresos preparatorios del nacional, se produjeron quiebres y retiro de delegaciones. El de Santiago fue uno de ellos, ya que hubo problemas con la representación de los estudiantes fiscales y los particulares; finalmente la FESES se retiró del encuentro, lo que fue recriminado por los dirigentes cercanos a la UP 39

En el Congreso Nacional de Educación, que contó con la participación de casi mil delegados, no hubo quiebre; los representantes estudiantiles se hicieron presente, incluyendo una delegación de la FESES, según lo consignó la prensa. En el debate participaron algunos hijos de importantes dirigentes políticos, como Andrés Palma Irarrázaval (hijo de Ignacio Palma) y Luis Mariano Irureta Uriarte (hijo de Narciso Irureta $)^{40}$.

Como hemos afirmado antes, en esta etapa la FESES no tuvo una actitud de abierta oposición al Gobierno. De hecho, durante el verano de 1972 participó en los trabajos voluntarios, junto a otras organizaciones de secundarios. La FESES y la FEITECh, por ejemplo, confluyeron en las obras de una represa en Cabildo. También se comprometió con la campaña de hermoseamiento de Santiago, con ocasión de la conferencia mundial de la UNCTAD. Su consigna era no caer en la politización de las anteriores directivas ${ }^{41}$. En el ambiente de la época, sin embargo, el hermoseamiento de la ciudad no fue finalmente una actividad tan "neutral". Aunque el enfrentamiento no fue directo, la prensa destacó la existencia de dos iniciativas paralelas con un fin similar: preparar la ciudad para el encuentro internacional. Participaron, sin coordinación, la FESES y las brigadas de la UP, aunque la FESES alegó la autoría de la idea. Finalmente, no hubo enfrentamientos entre ambos grupos, a pesar de la masiva participación en los trabajos ${ }^{42}$.

En marzo, todavía la FESES anunciaba la realización de un desfile para recibir a las delegaciones de la UNCTAD, en "representación" de la juventud chilena ${ }^{43}$, pero el clima pronto se enrareció y la idea de marchar cambió radicalmente de sentido. Silenciosamente, algunos sectores venían fraguando una política más rupturista. Con ese objetivo, Andrés Allamand dejó su colegio particular (el exclusivo

39 “Aún pena la derrota: FESES aclara falsas acusaciones hechas por la Unidad Popular”, op. cit.

40 "Con análisis de temas claves finaliza hoy Congreso de Educación", en La Prensa, 16 de diciembre de 1971, 5; "Congreso de Educación. Encerrona que terminó en empate", en Qué Pasa 36, 23 de diciembre de 1971, 13-14.

41 "Trabajo voluntario: Las manos jóvenes construyen Chile", en Mayoría 14, 19 de enero de 1972, 24-25; “Campaña de la Feses. 4.000 brochas para 'adecentar' Santiago”, en Qué Pasa 42, 3 de febrero de 1972, 11. En julio de ese mismo año, la FESES participó en una campaña de reforestación impulsada por la Municipalidad de Santiago, encabezada por el radical Ignacio Lagno Castillo. "FESES colabora en plantación de árboles", en La Prensa, 11 de julio de 1972, 13.

42 "En concentración de FESES. Secundarios dieron partida a trabajos voluntarios en colaboración con UNCTAD III", en La Prensa, 21 de marzo de 1972, 9; "La UNCTAD y el aseo de la ciudad", en La Prensa, 25 de marzo de 1972, 3; "Colaboración a UNCTAD III: En forma entusiasta secundarios iniciaron trabajos voluntarios", en La Prensa, 28 de marzo de 1972, 6; "UP se opone a que le saquen la mugre", en La Prensa, 29 de marzo, 1972, 1 y 7; "Clausurados trabajos voluntarios de FESES", $L a$ Prensa, 31 de marzo de 1972,1 y 8.

43 "Clausurados trabajos voluntarios de FESES", op. cit. 
Saint George) y se matriculó en el Liceo Lastarria, para así involucrarse de un modo más decisivo en la movilización social de los secundarios, que pronto se desató.

A diferencia de Allamand, que siempre se había definido en contra del proyecto de la Unidad Popular, Artaza transitó, entre 1970 y 1972, desde un entusiasta apoyo al proceso de cambio revolucionario hacia una posición de radical oposición. En su opinión, gran parte de los dirigentes democratacristianos de la FUEP experimentaron un proceso similar. Su militancia en la JDC habría ayudado a inclinarlos hacia posiciones más críticas y finalmente de abierta oposición ${ }^{44}$.

A mediados de abril de 1972, en medio de la expectación que produjo la Marcha de la Democracia (la primera actividad masiva y unitaria convocada por la oposición) y un día antes del acto de inauguración de la conferencia de la UNCTAD, la FESES resolvió convocar a un paro para protestar contra el Ministerio de Educación, entonces encabezado por Alejandro Ríos Valdivia. Las razones entregadas eran la escalada de tomas de liceos por parte de la ultraizquierda y la ineficacia del Ministerio para enfrentarlas, la falta de presupuesto universitario y sus efectos sobre la matrícula y las dificultades de infraestructura y dotación de material didáctico. Después de tres meses de conversaciones, y no habiendo soluciones, se decretó un paro por 24 horas. El día acordado, el 12 de abril, lo más destacado de la movilización fue una marcha realizada por la Alameda, de ocho cuadras de largo, según la prensa opositora ${ }^{45}$.

Los dirigentes de izquierda de la FESES rápidamente calificaron el paro de "politiquero". Aunque según ellos este no había logrado mayor adhesión (calcularon un 20\%), su claro propósito había sido preparar el ambiente de la anunciada Marcha de la Democracia. Las tomas de establecimientos por parte de la ultraizquierda, que de paso fueron condenadas por ser inconducentes, solo habían servido de excusa ${ }^{46}$.

El tema de mayor sensibilidad durante ese primer semestre de 1972 fueron las tomas de liceos y la designación de directores de establecimientos. Varios conflictos comenzaron a surgir por ese motivo, ya sea para apoyar a un director opositor al Gobierno que era desplazado o para criticar la designación de uno proclive a la UP. Con el inicio de las tomas y los paros, otro elemento de roce con la autoridad fue el de las sanciones.

Por ejemplo, a fines de mayo, el Liceo 9 de Hombres (en calle Catedral 4681) fue tomado por grupos DC, en protesta por la aplicación de sanciones a alumnos de esa militancia. La medida disciplinaria, aplicada por el consejo de profesores, fue calificada como una evidencia de "sectarismo" y persecución política, ya que los

44 Osvaldo Artaza, entrevista con el autor, 19 de mayo de 2009.

45 "Hoy 70.000 estudiantes a la huelga. Feses en acción", en La Prensa, 12 de abril de 1972, 19; "Acusan estudiantes: 'Ineficacia e irresponsabilidad del Ministerio no ha permitido solución de nuestros problemas", La Prensa, 13 de abril de 1972, 5.

46 En la prensa revisada no encontramos noticias de las tomas organizadas por la ultraizquierda. "Tomas de locales escolares no es la forma de solución", en El Siglo, 11 de abril de 1972, 7; "Paro acordado por FESES es un acto politiquero", en El Siglo, 13 de abril de 1972, 3. 
profesores y los alumnos eran en su mayoría de la UP. Aunque un grupo del FER (MIR) trató de "retomar" el establecimiento, no lo logró ${ }^{47}$. La FESES intentó mediar en este y otros incidentes, pero el Ministro no accedió a conversar en estas condiciones. Es más, ordenó que se computaran las inasistencias a clases en caso de huelgas y paros $^{48}$.

La FESES decidió entonces conversar directamente con Allende, quien les concedió una audiencia. Días antes, el Presidente había sido objeto de manifestaciones en su contra por parte de algunos secundarios y la FESES comenzó la audiencia dando excusas por el incidente. Allende se mostró abierto a que las conversaciones con el Ministro se reiniciaran y prometió gestiones para que no hubiera sanciones en contra de los alumnos que habían participado en el paro del 1 de junio, convocado por la FESES. A raíz de este diálogo, la Federación ordenó levantar el paro decretado por algunos establecimientos y el fin de dos de las tres tomas ${ }^{49}$.

Pero el ministro Ríos no contribuyó a prolongar este clima, ya que poco después envió una circular en donde fijó los procedimientos para evitar las huelgas y las tomas. Se debía comenzar con reuniones con padres, apoderados y alumnos, pero si estas no producían efectos positivos y se organizaban tomas de establecimientos, se debía pedir la colaboración de Carabineros para desalojar a los alumnos. El derecho a huelga, en el caso de los estudiantes, no existía. La circular, finalmente, fue dejada sin efecto, pero el hecho demostró la errática política que se aplicaba hacia la FESES. Poco antes de que Ríos abandonara el Ministerio, la directora de Educación Secundaria, Aída Migone, volvió a insistir en el diálogo y la participación. Incluso informó que había intercedido en el caso de los alumnos del Liceo 9, prometiendo que su situación se volvería a tratar en el consejo de profesores de dicho establecimiento ${ }^{50}$.

Los secundarios partidarios del Gobierno no dieron muestras de respaldo al Ministro. Los comunistas, por ejemplo, hablaron de la necesidad de un cambio en el método de trabajo del Ministerio. Aunque las críticas se enfocaron principalmente contra la directiva de la FESES (por ejemplo, en una marcha del 8 de junio), también demandaron mayor participación del Ministerio y un cambio en el estilo ${ }^{51}$.

47 "Mientras no se haga justicia, cabros democráticos del Liceo 9 no soltarán establecimiento", en La Prensa, 1 de junio de 1972, 7.

48 "En su segunda infancia a Ríos Valdivia le dio por ponerse sectario", en Tribuna, 1 de junio de 1972,24

49 Por entonces estaban en paro el Liceo 7 de hombres, un liceo de niñas, el Lastarria, el Instituto Nacional, el Mixto 26, la Consolidada de Buin y el Liceo de San Antonio. "De la goma que le tiraron y de otras cosas hablaron Allende y el mandamás de los secundarios", en Tribuna, 3 de junio de 1972, 12-13; "Allende recibió ayer a directiva de FESES" y "Paro fue politiquero", en El Siglo, 3 de junio de $1972,3$.

50 "De piquero se tiró Don Lolosaurio contra las huelgas estudiantiles", en Tribuna, 9 de junio de 1972, 6. “El Liceo 13. Hervidero estudiantil”, en Qué Pasa 73, 7 de septiembre de 1972, 13-14.

51 "Armados de palos y piedras desfilaron unos tontitos que se dicen estudiantes", en La Prensa, 9 de junio de 1972, 24. Las críticas comunistas en "JJCC impulsa educación científica, popular y democrática", en El Siglo, 1 de junio de 1972, 3; "Secundarios rechazan gestión de FESES" y "Basta a la utilización politiquera de FESES", en El Siglo, 9 de junio de 1972, 5 y 7. "Las FESES deben recoger el sentir de los estudiantes secundarios", en El Siglo, 11 de junio de 1972, 12. 


\section{El MiNisterio De Aníbal Palma}

Con el nuevo ministro Aníbal Palma, quien asumió a mediados de junio de 1972, se respiró un breve clima de diálogo, pero las tomas y las marchas no cesaron $^{52}$.

Por la misma época en Concepción, los estudiantes secundarios organizados en la FEPRESCO estaban bajo la influencia de la izquierda y comenzaron a participar en las movilizaciones que llevaron a la constitución de la Asamblea Popular de Concepción, originalmente creada para frenar el protagonismo de la oposición en las calles ${ }^{53}$.

A partir de agosto de 1972 hubo una mayor presencia pública de la Federación Única de Estudiantes Particulares (FUEP), que comenzó a confluir con la FESES en sus acciones, como veremos más adelante. En agosto realizó su segundo congreso provincial y eligió a su nueva directiva, la que quedó encabezada por José Manuel Correa, estudiante del Liceo Alemán. Una de las conclusiones a la que llegó la organización fue rechazar el proyecto de democratización que estaba promoviendo el Gobierno, ya que solo otorgaba un carácter consultivo a la participación de los alumnos. Por entonces, esta federación agrupaba a 32 colegios de la capital $^{54}$.

La etapa más crítica en las movilizaciones se vivió a partir de agosto. Ese mes, por ejemplo, las alumnas del Liceo 13 de Niñas se tomaron el establecimiento, en protesta por la designación de Mirta Castillo como directora titular, quien había tenido problemas con algunas alumnas y profesores en su calidad de interina. Las negociaciones con el Ministerio no fructificaron y la FESES llamó a un paro de advertencia para el lunes 21 de agosto. Para ese mismo día ya estaba convocado el primer paro del comercio contra el Gobierno y, aunque los incidentes mayores corrieron por cuenta de este último conflicto, a raíz del paro de los secundarios también hubo incidentes entre partidarios y opositores al movimiento ${ }^{55}$.

Pero la situación más compleja vino en los días siguientes, cuando la FESES (por mayoría de sus dirigentes) acordó aprobar un nuevo paro, debido a que el problema con la designación de directores no encontraba solución. La complejidad de esta convocatoria radicaba en el hecho de que Santiago había sido declarada zona de emergencia, a raíz de los serios incidentes del día lunes, lo que implicaba la prohibición de realizar manifestaciones callejeras. Frente a ese dilema, se permitió que Yunge hablara por cadena de emisoras radiales, para explicar que los

52 "El Liceo 13. Hervidero estudiantil", op. cit.

53 Mauricio Muñoz y Gabriel Moreno, Poder Popular en Chile, 1968-1973. Concepción y desarrollo de una estrategia revolucionaria, tesis para optar al título de profesor de Estado en Historia y Geografía, Universidad de Concepción, Concepción, 1992.

54 En la directiva de la FUEP, además de Correa, figuraban Andrés Barahona (vicepresidente, alumno del Colegio Luis Campino), José Tomás Castro (secretario general, del Liceo Alemán) y Claudia Delgado (tesorera, del Universitario Salvador). "Congreso de Estudiantes Particulares analizó sus numerosos problemas", en La Prensa, 30 de agosto de 1972, 4.

55 "Sin visos de solución la toma del Liceo 13", en La Prensa, 21 de agosto de 1972, 12; "Paro de advertencia realizó totalidad del alumnado secundario", en La Prensa, 22 de agosto de 1972, 7. 
estudiantes debían permanecer en sus casas, absteniéndose de realizar manifestaciones en las calles ${ }^{56}$. Como el Ministerio no cedió ante la presión, los incidentes se agudizaron en los días siguientes entre partidarios y opositores al Gobierno, como ocurrió en el Liceo Juan Antonio Ríos, con tomas y retomas. En el caso del Liceo de Niñas Gabriela Mistral, la decisión mayoritaria fue paralizar, en rechazo al paro de la FESES. El Gobierno decidió que el Liceo 8 de Hombres acogería a las alumnas del Liceo 13 en toma, para evitar la pérdida del año. Esto amplificó aún más el conflicto, porque la policía (por indicación del ministro Palma) intervino para asegurar que el local no fuera ocupado (lo que significó algunos roces con los dirigentes de la FESES), todo lo cual condujo a que los alumnos del Liceo 8 se trenzaran en una batalla por el control del establecimiento ${ }^{57}$.

Desde entonces, las movilizaciones fueron en ascenso. La demanda específica quedó entrampada en un punto muerto, ya que el Gobierno defendía su atribución para nombrar a los directores y los estudiantes exigían tener participación en su elección. Entre los propios partidarios del Gobierno no había consenso respecto a este punto, ya que no faltaron quienes, sin estar de acuerdo con las tomas, se mostraron reacios a respaldar todas las designaciones ${ }^{58}$.

El martes 29 de agosto, la FESES organizó una marcha por el centro de Santiago que terminó en incidentes frente al Ministerio, cuando una lluvia de piedras quebró los vidrios del edificio. La columna marchó por el centro y se enfrentó con los universitarios, quienes -a la cabeza de Alejandro Rojas- habían llamado a movilizarse contra la sedición y el fascismo, además de "recuperar las calles" para la izquierda. La envergadura de los incidentes llevó a que esa noche el Ministro hablara por cadena radial ${ }^{59}$.

En forma paralela, los conflictos locales en algunos establecimientos siguieron expresando cierto descontento, generalmente bajo la forma de demandas gremiales ${ }^{60}$, pero el mayor incidente estalló el viernes 1 de septiembre, con ocasión de una nueva marcha convocada por la FESES. La organización había llamado a un

56 Según el diario La Prensa, la votación interna en la FESES arrojó un apoyo casi unánime a la huelga: 52 votos a favor, uno en contra (el Liceo 6) y 4 abstenciones. "FESES aprobó la huelga", en La Prensa, 23 de agosto de 1972, 17.

57 "Heridos y destrozos en retoma de Liceo" y "Heridos y destrozos en guerrillas estudiantiles", en La Prensa, 25 de agosto de 1972, 1 y 9; "Peligrosa decisión del Ministro Palma. Clases del Liceo 13 se harán en el N 8", en La Prensa, 27 de agosto de 1972, 6; "Miristas se toman el plantel. ¡Graves incidentes en el Liceo $N^{\circ} 8$ !", "Heridos y presos. Batalla campal en Liceo 8" y "Dijo Sub del Interior: Carabineros actuó a pedido del Ministro de Educación en Liceo 8", en La Prensa, 29 de agosto de $1972,1,8$ y 17 .

58 Esto quedó patente en la agitada asamblea del 26 de agosto de 1972, que enfrentó a todas las partes involucradas en el conflicto del Liceo 13, cuyo debate aparece resumido en: "Peligrosa decisión del Ministro Palma. Clases del Liceo 13 se harán en el $\mathrm{N}^{\circ} 8$ ", op. cit.

59 "Violencia en las calles. FECH atacó concentración de la FESES" y "Clases con Carabineros anunció Aníbal Palma”, en La Prensa, 30 de agosto de 1972, 9 y 20.

60 El Liceo 4 de Niñas fue tomado en demanda de un gimnasio. Un grupo de alumnos del cercano Liceo Valentín Letelier se les enfrentó. Otros liceos decretaron paro indefinido (el Lastarria, y los liceos 9 y 14 de Hombres). Mientras, el Liceo 8 funcionó con "normalidad", aunque con resguardo policial. En sus aulas tuvieron clases cerca de un tercio de las alumnas del Liceo 13, que continuaba en toma, así como lo estaban los liceos 12 y 17 de Hombres. "Cobarde atentado contra liceanas: Hay tres heridas", en La Prensa, 31 de agosto de 1972, 9. 
paro de 48 horas, que continuaría el lunes, con posibilidades de prorrogarse. Las demandas seguían siendo las mismas, en torno al conflicto del Liceo 13 y al intento de quebrar el movimiento mediante el reinicio de clases en el Liceo 8. Esta marcha coincidió con otra de los estudiantes técnicos e industriales, en apoyo al Gobierno, pero, mientras la marcha de la FESES fue disuelta por Carabineros, con abundante uso de gases lacrimógenos, la segunda llegó al Ministerio y fue recibida por el titular. En la tarde, los incidentes alcanzaron mayor dimensión y el centro se transformó en un gran "campo de batalla", pero sin la presencia de escolares, sino de jóvenes mayores y adultos pertenecientes a grupos más radicalizados, así como delincuentes y "lumpen”, según lo denunció el propio Gobierno. El clima sicológico fue de alarma, ya que en algunas radios circuló la información de que en las poblaciones se estaba llamando a ir al centro a defender al Gobierno ${ }^{61}$.

Tras la violenta jornada, la FESES acordó mantener el llamado a paro para el día lunes 4 , pero sin asistir a clases, evitando así manifestaciones que pudieran desembocar en incidentes ${ }^{62}$.

El compás de espera duró poco, ya que el miércoles 6 de septiembre los estudiantes de colegios particulares (agrupados en la FUEP) convocaron a un paro y a una marcha por el centro, en apoyo a la FESES. Aunque la marcha misma se realizó en orden, en la tarde volvieron a estallar serios incidentes con la policía, que tuvieron como saldo un muerto (un joven de 17 años, Mario Avilés). El recién elegido presidente de la FUEP, José Manuel Correa, aclaró que los estudiantes no habían participado en las acciones violentas, sino grupos de extrema izquierda y extrema derecha. La prensa también destacó que los incidentes no fueron promovidos por los estudiantes, sino por "extremistas" y "lumpen". Obviamente, el origen de los desmanes era atribuido a la provocación de unos y otros, según la orientación política de los diarios ${ }^{63}$. El Comité Ejecutivo de la FESES lamentó la muerte del estudiante (que no estaba participando en las movilizaciones) y llamó a concurrir a clases al día siguiente (jueves 7), "para permitir que el clima de tensión se relaje". Sin embargo, hizo un llamado para estar alerta ante futuras movilizaciones ${ }^{64}$.

Poco después, la larga y emblemática toma del Liceo 12 de Niñas, ubicado en calle Lo Encalada, llegó a su fin. La "retoma" del liceo provocó gran conmoción, porque cerca de trescientos muchachos comunistas se trenzaron en una refriega con los ocupantes en la madrugada del 23 de septiembre. Finalmente, el liceo fue desalojado y entregado a Carabineros. El incidente dejó numerosos heridos y provocó una guerrilla de acusaciones y réplicas en la prensa. Los diarios de oposición

61 La prensa se trabó en una polémica sobre el origen de los desórdenes y el "vandalismo". Véase La Tercera, La Prensa y El Siglo, de 2 y 3 de septiembre de 1972.

62 "FESES pide a estudiantes no salir hoy", en La Prensa, 4 de septiembre de 1972, 13.

63 Amplio detalle en La Prensa, 7 de septiembre de 1972, 1, 6 y 8-9.

64 "Declaración: FESES lamenta trágica muerte de joven Avilés", en La Prensa, 8 de septiembre de 1972, 4. Un balance sobre el conflicto en "Política y violencia (capítulo de la semana)", en Qué Pasa 74, 14 de septiembre de 1972, 7; "Un conflicto “iceberg"”, en Qué Pasa 77, 5 de octubre de 1972, 43-44. 
calificaron la toma de "masacre" y "sanguinario asalto" e incluso afirmaron que la mascota de los ocupantes, bautizada "Palmita", había sido degollada por la "barbarie marxista". Las alumnas partidarias de la UP lo mostraron vivo a la prensa y lo rebautizaron "Docito". La UP mostró las armas y las bombas que guardaban los ocupantes ${ }^{65}$.

Las críticas arreciaron en contra del ministro Palma, quien se hizo presente en el lugar esa misma noche. La oposición pidió su renuncia. Ante el ambiente que se creó (incluso un parlamentario lo tildó de "mequetrefe"), Palma presentó su renuncia al Presidente, pero este lo confirmó. En protesta por los hechos, la FESES organizó un paro el 27 de septiembre, en conjunto con la FEUC y los estudiantes particulares. El acto central se realizó en el Estadio Chile, con 5 mil estudiantes. Por su parte, los secundarios partidarios de la Unidad Popular (quienes calificaron de fracasado el paro) marcharon por el centro en apoyo al Ministro, bajo el grito “¡tomas, no; clases, sí!”66.

A estas alturas, si bien muchas demandas seguían siendo gremiales, el enfrentamiento principal era político. Las disputas dentro de la FESES llevaron a que, a comienzos de octubre, la directiva organizara un plebiscito que definiera el apoyo a la posición de la directiva (tesis 1) o el respaldo al ministro Palma (tesis 2). Inicialmente, la directiva afirmó que habían participado cerca de 60 mil estudiantes, aunque luego las cifras oficiales entregadas sumaron 21.700 votos, de los cuales dos tercios correspondieron a liceos de niñas, lo que parece indicativo del respaldo femenino con que contaba la directiva ${ }^{67}$. Los secundarios cercanos a la UP objetaron el plebiscito y no lo respaldaron (aunque algunos estudiantes gobiernistas sí participaron), argumentando que las próximas elecciones internas serían la ocasión para medir fuerzas ${ }^{68}$.

El paro convocado para el 3 de octubre de 1972 fue mucho más violento que los anteriores: estuvo acompañado de manifestaciones callejeras con marchas, barricadas y enfrentamientos con piedras. Los motivos fueron nuevamente el rechazo al nombramiento de las autoridades de algunos establecimientos y los hechos ocurridos en el Liceo $12^{69}$.

Por entonces, Lina Rivas, vocal comunista de la FESES, hacía ver las sospechosas coincidencias entre las movilizaciones gremiales y las coyunturas políticas nacionales: el primer paro se había organizado junto con la Marcha de las Ollas Vacías (el 1 de diciembre de 1971); el segundo, cuando se realizaba la Marcha de

65 Abundantes noticias en El Siglo, 24 de septiembre de 1972, 1 y 3; 25 de septiembre de 1972 , 1, 3 y 9; 26 de septiembre de 1972, 1, 3 y 8; La Segunda, 23 de septiembre de 1972; El Mercurio, 23 de septiembre de 1972, 1 y 8; 24 de septiembre de 1972, 17.

66 “¿Déjennos estudiar!”, "Secundarios se movilizaron en defensa de su año escolar”, "Peligra Prueba de Aptitud Académica por ola de paros" y "Parcial paro político de FESES y FEUC", en El Siglo, 28 de septiembre de 1972, 1, 3, 7 y 9 .

67 Según los datos aportados por la prensa, en el plebiscito participaron 28 liceos: de ellos, 19 de niñas y 9 de hombres. "Un conflicto "iceberg'", op. cit.; "Resultados del plebiscito de FESES", en El Mercurio, 8 de octubre de 1973,31 .

68 En varias ocasiones deslegitimaron el plebiscito. El Siglo, 27 de septiembre de 1972, 3; 3 de octubre de 1972, 3 .

69 Amplias noticias en El Siglo, 4 de octubre de 1972. 
la Democracia (12 de abril de 1972); el siguiente había coincidido con el paro de comerciantes (21 de agosto de 1972); y el último con el asalto a la sede del PC, aunque el hecho más significativo se produjo días después, con el paro de los camioneros $^{70}$.

Hacia fines de 1972, la consigna de los estudiantes de la Unidad Popular era salvar el año escolar. Así era, por lo menos, entre los sectores más moderados, como el Partido Comunista, que buscaba recuperar la normalidad en las clases y terminar con la escalada de tomas. Para ello, se convocó a crear comités de Defensa del Año Escolar. Con esa consigna se organizó un acto en el Estadio Chile, el viernes 6 de octubre, en el cual participaron el Sindicato Único de Trabajadores de la Educación (SUTE), la Asociación Nacional de Centros de Padres y Apoderados (encabezada por Raúl Boudet), la Central Única de Trabajadores (CUT), el Ministerio de Educación y los dirigentes estudiantiles secundarios de la UP, liderados por Camilo Escalona ${ }^{71}$.

En la multitudinaria concentración que realizó la oposición el 10 de octubre en plena Alameda, destacó, según la prensa de derecha, la presencia de los secundarios y las mujeres, pero al día siguiente, el paro de los camioneros (que a partir de entonces se generalizó) desplazó el interés noticioso por los secundarios.

En noviembre, poco antes de realizarse las elecciones de la FESES, finalmente el ministro Palma firmó el decreto que buscaba normar la democratización de la enseñanza, un tema largamente anunciado. En el texto se crearon varios niveles de participación, en el plano nacional, provincial y local. Sin embargo, el clima estaba ya enrarecido y las sospechas de manipulación gubernamental no se hicieron esperar. Los dirigentes de la FESES manifestaron su desacuerdo, interrumpiendo la ceremonia de firma ${ }^{72}$.

Según Qué Pasa, la democratización de la educación ya no era concebida como una ampliación de la cobertura, sino también como un incremento de los mecanismos de participación social en todo el proceso de formación. El esquema propuesto por el Gobierno era

"una mezcla de la incontenible marea 'participante' que recorre el país con el mecanismo que algunos de la UP insisten en aplicar allí donde pueden, sea en fábricas, establecimientos hospitalarios o colegios. En efecto, muy en la tradición de los 'soviets', buscan las direcciones colegiadas con determinante participación obrera, pero sujetas siempre a un poder superior que en definitiva decide todo lo importante"73.

En el caso particular de la FESES, esta podría participar en los niveles regional, provincial y local, pero no para discutir los asuntos de fondo relacionados con la

70 "Dirigentes estudiantiles de la UP denuncian. FESES usó como mascaradas problemas de liceos 12 y 13", en El Siglo, 5 de octubre de 1972, 3.

71 El desalojo del Liceo 12 marcó, al parecer, el inicio de la consigna. Detalles del acto en: "Defensa de la normalidad del presente año escolar", en El Mercurio, 7 de octubre de 1972, 27, y El Siglo, 7 de octubre de 1972, 11.

72 "El último decreto de Aníbal Palma", op. cit.

73 Idem. 
reforma educacional en su conjunto, ya que al Consejo Nacional de Educación se invitaría en forma permanente solo a los representantes de las federaciones estudiantiles de carácter nacional ${ }^{74}$.

El proceso de democratización tuvo problemas adicionales. La Contraloría objetó la legalidad del decreto y recién en marzo del año siguiente se formalizó la firma, en un clima aún más hostil.

\section{LA REÑIDA ELECCIÓN DE LA FESES (1972)}

En este clima, la elección de la directiva, en noviembre de 1972, reanimó el conflicto por controlar la FESES. La Democracia Cristiana quiso demostrar que la conducción de la Federación la hacía merecedora de continuar en ese lugar. El significativo avance que había logrado en la conducción de los centros de alumnos la hacía estar segura del triunfo y de no necesitar aliarse con la derecha. En vísperas de la elección, afirmaba que controlaba 45 centros de alumnos de los 66 liceos afiliados a la FESES (Barros Borgoño, Valentín Letelier, Gabriela Mistral, liceos 1, 2, 4 y 8 de Niñas y Liceo 8 de Hombres, por citar algunos), mientras la UP lo hacía sobre 14 (incluyendo, al parecer, la Consolidada Dávila y el Liceo 6 de Hombres; el Manuel de Salas lo había perdido); los nacionales dominaban en 6 (entre ellos, el Liceo 5 de Niñas y el 11 de Hombres); y el MIR controlaba solo uno (el Liceo 25 de Conchalí, antiguo Che Guevara) ${ }^{75}$. De ser efectivas estas cifras, era previsible una clara victoria de la $\mathrm{DC}^{76}$.

La Juventud Nacional (JN), aunque intentó crear una lista conjunta de oposición, finalmente no recibió respuesta y levantó una candidatura propia, autodenominándose la "Juventud firme" o bien "Los firmes", en alusión a su actitud intransigente. El avance de los nacionales ya era notorio antes de la elección, con triunfos en algunos liceos donde antes no tenían presencia ${ }^{77}$.

La izquierda, por su parte, levantó con gran entusiasmo la consigna: "Recuperar la FESES para el pueblo y los estudiantes". Si efectivamente estaba en minoría, como lo afirmaba la DC, esto no se reflejó en el ánimo de la campaña.

Finalmente se presentaron cinco listas: una de la JDC, que llevaba como candidato a Miguel Salazar; otra de la Unidad Popular, encabezada por Camilo Escalona, joven socialista; el FER levantó la candidatura de Luis Valenzuela, del MIR; la Juventud Nacional, con algunos aliados menores (como la Democracia Radical y el

74 Idem

75 “Mayoría DC en los liceos”, op. cit.; “¿Euforia en liceos durante la visita de Miguel Salazar!”, en La Prensa, 16 de noviembre de 1972, 7. "Actas firmadas por delegados UP dan fe de nuestro triunfo", en La Prensa, 18 de noviembre de 1972, 5. Sobre los centros de alumnos controlados por la UP, no tenemos claro cuáles eran. Sabemos de la pérdida del Manuel de Salas, bastión de la izquierda durante algunos años: "Mordieron el polvo miricones del Liceo Manuel de Salas", en Tribuna, 3 de junio de $1972,24$.

76 Lo único que podía compensar el predominio DC era el tamaño de los establecimientos que estos controlaban.

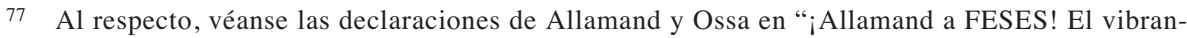
te grito de los Jóvenes firmes en el Normandie", en Tribuna, 8 de noviembre de 1972, 10 y 15. 
PADENA) llevó a Andrés Allamand; y finalmente el Movimiento Espartaco (pequeño grupo maoísta) presentó como candidata a María Eugenia Román.

La campaña fue mucho más tensa que la del año anterior. La derecha levantó una candidatura bastante beligerante, sobre todo tras la golpiza que recibiera Sergio Onofre Jarpa en la Universidad Técnica del Estado. "A los cobardes les daremos su merecido", señaló Allamand en uno de sus discursos, a lo que agregó, "vamos a volver a la UTE para responder a la violencia con la violencia". Terminó recordando el lema del Comando Rolando Matus, "ojo por ojo, diente por diente" 78 .

La Unidad Popular, por su parte, se concentró en resaltar no solo su propia propuesta programática, sino también los errores de conducción de la DC. El programa de la lista de Escalona significó una postura de apoyo al Gobierno, pero además planteó algunas demandas sectoriales, como la derogación del decreto 558 de principios de 1970 (herencia del gobierno de Eduardo Frei), para hacer más autónomos los centros de alumnos, y la formación de consejos de la Comunidad Escolar, algo que estaba contemplado en la reforma que estaba estudiando el Gobierno ${ }^{79}$.

La envergadura de la elección fue tal que, además de los foros y proclamaciones en los liceos, los candidatos aparecieron debatiendo por radio y televisión. Aunque en la campaña hubo algunas escaramuzas, en general no hubo denuncias de grandes incidentes ${ }^{80}$. Lo que se decidía no era menor, ya que en el acto electoral podían votar entre 70 y 80 mil estudiantes (sobre un universo de 120 mil secundarios fiscales), provenientes de los 67 liceos de la provincia que estaban afiliados a la FESES ${ }^{81}$. La prensa de los distintos grupos políticos se alineó con sus abanderados, ofreciendo sus páginas con abundante propaganda. Tribuna, por ejemplo, incluyó un afiche que cubría dos páginas y El Siglo editó un suplemento especial ${ }^{82}$. La campaña propagandística alcanzó grandes dimensiones: además de proliferar los carteles en las calles, las estudiantes partidarias de la DC salieron a las calles con poleras blancas con el rostro de Salazar ${ }^{83}$.

El resultado final de la elección arrojó un resultado ambiguo, ya que las cifras oficiales del Tribunal Calificador de Elecciones fueron impugnadas por la izquierda. Oficialmente, de los 15 cargos que componían el ejecutivo de la FESES, nueve recayeron en la DC, cuatro en la UP y dos quedaron en manos de la JN. Pero este

78 "Allamand: "A los cobardes les daremos su merecido", en Tribuna, 10 de noviembre de $1972,13$.

79 La demanda de derogación del decreto 558 ya había sido planteada, en junio de ese año, por la izquierda. "Paro fue politiquero", op. cit.; "Candidatos UP denunciaron hoy graves irregularidades en elección de FESES", en El Siglo, 14 de noviembre de 1972, 16.

80 "Cobardes agresiones contra candidatos nacionales a FESES. Embestida comunista arrecia en los frentes estudiantiles", en Tribuna, 11 de noviembre de 1972, 12-13.

81 La cifra total estimada de votantes aparece mencionada en varios periódicos. El número de liceos lo menciona El Siglo, 12 de noviembre de 1972, 14. El universo total lo menciona Tribuna, 15 de noviembre de 1972,7 .

82 El suplemento especial FESES de El Siglo (que se vendía en forma independiente) se anunció en la edición del 13 de noviembre, 3, pero no está en la colección de la Biblioteca Nacional.

83 "FESES: expropiaciones", en La Prensa, 16 de noviembre de 1972, 7. 
fallo se produjo cuando ya los representantes de la lista de la UP se habían retirado de la sede de calle Fanor Velasco, tras serios incidentes. Camilo Escalona (JS) y Miguel Salazar (JDC) se autoproclamaron simultáneamente ganadores de la elección y con ello hubo públicamente dos presidentes de la FESES.

La Unidad Popular celebró en las calles la victoria. La FESES había sido "recuperada" para los estudiantes y el pueblo, tarea que se habían planteado durante la campaña. El Siglo calificó el triunfo de "aplastante" e "irrebatible", aunque alertó que la directiva DC pretendía robarlo. Valiéndose de sus propios cómputos, publicó los resultados finales ${ }^{84}$.

La Unidad Popular y la derecha hablaron de irregularidades en las elecciones: impresión de más votos de los necesarios y sin numerar (se mencionaba la impresión de 140 votos), la tardía entrega de las listas de votantes y de liceos participantes, además de la composición del Tribunal Calificador de Elecciones, controlado por la directiva saliente. Tras la elección se habrían encontrado votos en favor de la lista DC botados en el suelo. En esto hubo relativa coincidencia entre la izquierda y la derecha, con la salvedad de que la JN también criticaba que la UP hubiera tenido un plazo adicional para entregar su listado de firmas al momento de inscribir la candidatura $^{85}$. La UP denunció, además, el robo de actas, votos y urnas en algunos liceos, y la anulación fraudulenta por parte del TRICEL de los resultados en liceos proclives a la UP (como el INBA) ${ }^{86}$. Las denuncias de irregularidades por parte de la derecha fueron destacadas por la lista de la UP, tanto que incluso se llegó a afirmar, erróneamente, que la derecha había reconocido el triunfo de la izquierda ${ }^{87}$.

La lista de la Juventud Nacional estuvo lejos de endosar el triunfo a la UP. Al contrario, reconoció el triunfo de la DC, aunque consignando que su propia votación había sido mayor (la cifra se distanciaba en casi mil votos de la oficial) y resaltando el fracaso de la UP en casi todos los liceos, ironizando con la "risible" celebración de Escalona. Solo le reconoció el triunfo en tres establecimientos (Consolidada Dávila, Liceo 24, en la población La Habana, y Darío Salas). La lista de la JN, según sus propios cómputos, había triunfado en 12, entre ellos el 7 de Niñas y algunos de los más importantes de hombres (incluyendo el Manuel de Salas) ${ }^{88}$.

La Democracia Cristiana, por su parte, celebró con alborozo el triunfo aplastante de su lista. Según sus cálculos, la derecha había alcanzado mayoría en 11 liceos,

84 El Siglo, 16 de noviembre de 1972, 1 y 5; 17 de noviembre de 1973, 1, 3 y 5 .

85 "Candidatos UP denunciaron hoy graves irregularidades en elección de FESES", op. cit.; “¡Basta de irregularidades en FESES!”, en Tribuna, 14 de noviembre de 1972, 17; "Pese a las chuecuras, fue espectacular el avance de nacionales en FESES", en Tribuna, 17 de noviembre de 1972, 8; "La desvergüenza de la Unidad Popular", en Tribuna, 18 de noviembre de 1972, 4.

86 "Para ocultar su derrota, la DC preparó el fraude en FESES", en El Siglo, 17 de noviembre de $1972,16$.

87 "UP gana en FESES: Escalona presidente", en El Siglo, 16 de noviembre de 1972, 1 (aquí se lee: "Momios reconocen victoria de la izquierda”); “Hasta el PN reconoce el fraude en FESES!", en El Siglo, 18 de noviembre de 1972, 7.

88 Los triunfos que se adjudicaba la JN eran $\operatorname{los}$ liceos 1, 5, 7, 14, 17 y 20 de Niñas; Internado Nacional Femenino, Liceo 11 de Hombres, Instituto Nacional, INBA, Lastarria y Manuel de Salas. "Pese a las chuecuras, fue espectacular el avance de nacionales en FESES", op. cit.; "En 12 liceos la Juventud Nacional arrasó con papas y caldos: ¡Bravo!”, en Tribuna, 18 de noviembre de 1972, 2. “La desvergüenza de la Unidad Popular", op . cit. 
la UP lo había logrado en otros 11 y la DC no tenía contrapeso en 43 establecimientos. Todo esto le resultaba coherente con su fuerza en los centros de alumnos de estos mismos liceos ${ }^{89}$.

Además de celebrar su triunfo, la lista democratacristiana se defendió con firmeza de las acusaciones de las dos listas contrincantes. Recordemos que por entonces todavía estaba fresco el recuerdo de la polémica por los resultados en la elección de la CUT. Según la JDC, no había ambigüedad en las listas de votantes, solo se habían impreso 100 mil votos, los reglamentos estaban disponibles para todos y todas las listas habían tenido derecho a estar representadas en las mesas, en los tribunales locales y en el central. En cuatro liceos donde la DC era mayoría (9 y 13 de Niñas, Gabriela Mistral y Valentín Letelier), no se había podido realizar el escrutinio debido al robo de las urnas y ese era el origen de los votos esparcidos en la calle. Además, en las actas que se habían firmado en los diversos locales de votación, los partidarios de la UP habían estado de acuerdo con los resultados. Según la directiva democratacristiana, la "farsa" de desconocer los resultados estaba preparada de antes, como lo probaba el titular de Las Noticias de Última Hora, un diario vespertino socialista que dio por ganador a Escalona cuando todavía no se iniciaba el recuento de votos. Impugnó, además, la publicación detallada de los resultados por liceo que apareció en la prensa de izquierda y que decía basarse en las actas originales firmadas por todos los apoderados. La Prensa publicó su propia información, también aludiendo a las actas oficiales ${ }^{90}$.

\begin{tabular}{|c|c|c|c|c|c|c|}
\hline \multirow[b]{2}{*}{ votos } & \multicolumn{2}{|c|}{ Resultados TRICEL } & \multicolumn{2}{|c|}{ Comando PN } & \multicolumn{2}{|c|}{ Comando UP } \\
\hline & $\%$ & votos & $\%$ & votos & $\%$ & \\
\hline UP & 19.109 & 33,0 & 19.303 & 33,0 & 23.412 & 38,4 \\
\hline DC & 22.956 & 41,0 & 22.414 & 38,0 & 20.043 & 32,8 \\
\hline FER & 2.933 & & 2.841 & & 3.105 & 5,1 \\
\hline JN-DR & 11.213 & 18,3 & 12.190 & 21,5 & 13.791 & 22,6 \\
\hline Espartaco & 155 & & & & 133 & 0,2 \\
\hline Blancos & 200 & & & & 160 & 0,3 \\
\hline Nulos & 1.314 & & & & 370 & 0,6 \\
\hline TOTAL & 57.880 & & & & 61.014 & 100,0 \\
\hline
\end{tabular}

Fuente: Resultados Tricel: El Mercurio, 17 de noviembre de 1972, p. 1; Comando PN: Tribuna, 18 de noviembre de 1972; Comando UP: El Siglo, 17 de noviembre de 1972.

89 El total de establecimientos contabilizados es de 64. Suponemos que la diferencia se debe a que no todos los cómputos pudieron realizarse. "iSomos muchos más”, en La Prensa, 18 de noviembre de 1972,8 .

90 "Yunge responde acusaciones de candidatos de derecha", en La Prensa, 15 de noviembre de 1972, 5; "Espectacular triunfo de la DC en FESES" y "Miguel Salazar asume la próxima semana la presidencia de FESES", en La Prensa, 17 de noviembre de 1972, 7 y 20; "Declara vocal de FESES: Actas firmadas por delegados UP dan fe de nuestro triunfo", en La Prensa, 18 de noviembre de 1972, 5; "Grotesca maniobra UP" y "La descarada mentira de los diarios oficialistas", en La Prensa, 18 de noviembre de 1972, 1 y 17. Confróntese con los resultados detallados que se entregan en El Siglo, 17 de noviembre de 1972, 16. Los resultados del PN son incompletos y los porcentajes no resultan consistentes con los totales absolutos. 
Si comparamos los resultados de 1971 y 1972, es posible advertir que la cantidad de votantes aumentó notablemente. Del total de potenciales votantes, cercano a los 70 mil, los votos efectivos fueron 36 mil en 1971 y entre 57 y 61 mil en 1972. Aunque las cifras finales son difíciles de comparar, debido a que no hubo consenso sobre cuáles fueron los resultados reales, es posible llegar a ciertas conclusiones con base en las tendencias generales y los datos disponibles. La UP subió levemente de 36,7 a $38,4 \%$, según sus propios cálculos, aunque habría descendido según las restantes candidaturas, que le asignaban un 33\%. Según los datos oficiales del Tricel, la DC se mantuvo en torno al mismo porcentaje $(39,7 \%)$ de 1971 , aunque tanto la lista de derecha como de izquierda le asignaron una baja (la UP le atribuyó un $32,8 \%$, frente al 38\% del comando del PN). La propia DC hizo notar que seguía siendo la primera fuerza política dentro de los secundarios. En términos de crecimiento, la gran triunfadora fue la candidatura de derecha, que aumentó sorprendentemente de un $7,8 \%$ en 1971 a un $19,4 \%$ (resultado oficial) o bien a un $22,6 \%$ (según la UP) en 1972. Los grupos a la izquierda de la Unidad Popular se mantuvieron con escasa presencia electoral, conservando el respaldo de unos 3 mil votos.

\section{LA LUCHA FRONTAL DE LOS SECUNDARIOS}

El quiebre de la FESES fue un signo más del fuerte enfrentamiento que estaba tensionando a la organización, hasta entonces en un virtual equilibrio de fuerzas. En la nueva fase que se inició tras la reñida elección de noviembre de 1972, ya no quedó espacio para la negociación ni el aparente diálogo que existió durante el período anterior. El enfrentamiento se hizo mucho más directo.

Recordemos que la derecha había ganado terreno durante la presidencia de Yunge, lo que se reflejó en la elección de 1972. La estrategia de Andrés Allamand, líder indiscutido de esa vertiente, era de una abierta acción directa en las calles. Como lo graficó claramente en No virar izquierda (1974), especie de autobiografía novelada, las circunstancias de la época obligaban a pasar a la ofensiva callejera.

Miguel Salazar no se quedó atrás en este escenario, ya que su actitud fue de bastante confrontación y acción directa, en comparación con Yunge. Sin embargo, a este último le había correspondido actuar en un momento distinto, cuando el ambiente aún no estaba tan polarizado. La presidencia de Salazar, en cambio, fue expresión del clima predominante a fines de 1972 y $1973^{91}$.

La izquierda secundaria, por su parte, siguió enfrentada a dos tácticas: de enfrentamiento directo con la derecha, en las calles y en la toma de liceos; y de defensa del año escolar, es decir, a favor de la normalización de las actividades escolares. Al parecer, la FESES dirigida por Escalona adoptó la segunda estrategia, más bien moderada. Por ejemplo, en marzo de 1973, dio un pleno respaldo a la Escuela Nacional Unificada (ENU) y propuso dialogar con los estudiantes que no estaban de acuerdo con ella. Además se abocó a realizar trabajos voluntarios para

91 Osvaldo Artaza ve una continuidad entre ambos dirigentes, en entrevista con el autor, 19 de mayo de 2009. 
limpiar la ciudad y a organizar comités de estudiantes para vigilar los precios de los útiles escolares. Al parecer, esta federación funcionaba físicamente en el edificio Gabriela Mistral, muy cerca de las organizaciones afines al Gobierno ${ }^{92}$. Pero también había estudiantes de izquierda que demostraban mayor interés por enfrentar a los estudiantes de oposición en las movilizaciones que estos organizaban: frente a las "tomas", generalmente organizaban "retomas".

En marzo de 1973, Tribuna tituló “¡Empezó la resistencia estudiantil!”. La toma del Liceo Lastarria encendió la mecha ese año. La demanda específica se refería al nombramiento del nuevo rector ${ }^{93}$.

Pero el tema central que concentró la atención de los secundarios durante 1973 fue el proyecto de la ENU, cuyo texto fue presentado en enero de ese año, lo que abrió un nuevo flanco de críticas en la oposición.

En rigor, la anunciada reforma propiciada por la Unidad Popular había quedado en suspenso por propia iniciativa del Gobierno, el que proponía gestar una reforma desde abajo, con una amplia discusión de todos los sectores sociales involucrados, y no "desde arriba", como se le reprochaba a la reforma de Eduardo Frei. Sin embargo, también hubo una circunstancia política que retrasó significativamente el proceso: originalmente, el programa de la Unidad Popular contemplaba una intervención activa del Estado en materia educacional, que en la práctica significaría terminar con la educación privada, para evitar así las diferencias sociales entre ricos y pobres ${ }^{94}$. Sin embargo, tras la firma del Acuerdo de Garantías Constitucionales, el Gobierno se comprometió a no intervenir en la educación particular.

Durante el año 1971, la discusión sobre la reforma quedó radicada primero en los establecimientos (marzo y abril) y luego a nivel local y provincial (septiembre, octubre y parte de noviembre). En este debate participaron padres, estudiantes, profesores y trabajadores. Sin embargo, la oposición comenzó a reclamar que, en la asignación de las representaciones, se le daba una mayor presencia a las organizaciones proclives al Gobierno (como la CUT y el SUTE). Además, no siempre se respetaba la consignación por escrito de los votos de minoría. Con esta experiencia acumulada, a fines de 1971 se realizó el postergado Congreso Nacional de Educación 95 .

Durante el año 1972, el Gobierno se dedicó a elaborar su proyecto educacional, de acuerdo a las directrices planteadas en el Congreso. Como hemos visto al relatar las acciones de la FESES durante ese año, las movilizaciones estudiantiles oposito-

92 "FESES entregó pleno respaldo a Escuela Nacional Unificada", en El Siglo, 24 de marzo de 1973,8 .

93 Las críticas se dirigieron contra la nueva vicerrectora interina, la comunista Irma Covarrubias. El candidato opositor al cargo de rector era el inspector general Luis González. “¡Empezó la resistencia estudiantil!", en Tribuna, 28 de marzo de 1973, 8.

94 El Programa de la Unidad Popular señalaba al respecto: "Con el objeto de hacer realidad la planificación de la educación y la escuela única, nacional y democrática, el nuevo Estado tomará bajo su responsabilidad los establecimientos privados, empezando por aquellos planteles que seleccionan su alumnado por razones de clase social, origen nacional o confesión religiosa. Esto se realizará integrando al sistema educacional el personal y otros medios de la educación privada".

95 “Ante el Congreso Nacional de Educación. Las garantías que se esperan”, en Qué Pasa 31, 18 de noviembre de 1971, 40-41. 
ras se concentraron en el tema de la designación de las autoridades en los liceos. En 1973, en cambio, el acento estuvo puesto en el proyecto de la ENU, presentado en enero de ese año. Aunque el proyecto fue rápidamente postergado tras las presiones de la Iglesia y las Fuerzas Armadas, en la estrategia opositora se impuso la idea de que ese debía seguir siendo el centro de las movilizaciones.

Fue por esta época que se profundizó la campaña de prensa que denunciaba los alcances de la reforma. Según esta, los colegios particulares desaparecerían, se suprimirían las clases de religión, los alumnos serían concientizados desde pequeños, los trabajos voluntarios se transformarían en obligatorios y se proletarizaría al niño, convirtiéndolo en un trabajador. En definitiva, no era más que la "sovietización de la enseñanza"96. Osvaldo Artaza inicialmente había visto con simpatías la idea de reformar la educación y a lo largo de 1971 se sintió solidario con la idea del cambio, de terminar con la educación elitista y ampliar la participación en el sistema, pero en 1972 ya se había sumado a una posición contraria a la UP y visitaba los colegios haciendo campaña en contra de la ENU. A la distancia, no cree que el tema específico de la ENU haya sido decisivo. No importaba qué dijera realmente el proyecto gubernamental en esa materia, la desconfianza ya estaba instalada ${ }^{97}$.

La divulgación que el Gobierno comenzó a hacer de la ENU en marzo de 1973 pretendió revertir esta situación. Pero la campaña no rindió muchos frutos, si consideramos el discurso del ministro de Educación Jorge Tapia al comienzo del año escolar en 1973, por cadena de radio y televisión, que daba cuenta de cuánto había penetrado en la población ${ }^{98}$.

La postergación de la ENU fue considerada una maniobra para acallar las críticas, pero no para retrasar la aplicación del proyecto, sobre todo después de que se pusieran en marcha los consejos (locales, provinciales y regionales) de educación, se dictara la circular $\mathrm{N}^{\circ} 13$ para la enseñanza técnico-particular y comenzaran a realizarse planes de "adiestramiento" de monitores escolares, con el patrocinio de la CUT. "La ENU se detendrá con hechos", se leía en la página editorial de El Mercurio. El marxismo despreciaba la palabra empeñada y era capaz de utilizar todos los subterfugios para llevar a cabo sus planes. Por ello, era necesario actuar ${ }^{99}$.

En abril de 1973, una veintena de dirigentes de enseñanza media se reunieron con el ministro Jorge Tapia para discutir el proyecto de la ENU y el procedimiento para llevar a cabo el debate. La delegación estaba presidida por Miguel Salazar y contó también con la participación de dirigentes de los estudiantes de colegios particulares,

96 Así lo afirmaba, por ejemplo, Tribuna, 27 de abril de 1973, 6 y 7 (“¡Puchas que son encachados nuestros cabros!").

97 Osvaldo Artaza, cit.

98 El discurso fue emitido en la noche del domingo 25 de marzo de 1973, en víspera del inicio del año escolar. "Ministro Tapia en la iniciación del año escolar: No ayudar la nueva educación es oponerse a la patria", en El Siglo, 26 de marzo de 1973, 9; "El diálogo nacional está abierto, dice el Ministro Tapia: La Escuela Unificada está en pleno proceso de discusión”, en El Siglo, 27 de marzo de $1973,5$.

99 El Mercurio, 25 de abril de 1973, 5. 
agrupados en la FUEP, presidida por José Manuel Correa, y la Confederación Nacional de Estudiantes de Colegios Particulares (CODEPART), encabezada por Osvaldo Artaza $^{100}$. Esta última confederación había surgido claramente con el objetivo de dar dirección nacional al movimiento estudiantil contra Allende ${ }^{101}$.

En este clima, las movilizaciones alcanzaron niveles similares o quizás más violentos que los de octubre del año anterior. El 17 de abril, los estudiantes particulares decretaron un paro nacional, que afectó -según la prensa opositora- a 200 mil estudiantes a lo largo del país, incluyendo los 50 mil de Santiago. En la marcha que se organizó en la capital estaban presentes los máximos dirigentes a nivel nacional: Osvaldo Artaza, de la Confederación, y Correa, de la federación santiaguina ${ }^{102}$.

A fines del mes, las movilizaciones estaban extendidas a lo largo de las principales ciudades del país. Las federaciones de estudiantes de educación media comenzaron a movilizarse y a demostrar interés por negociar con el Gobierno, aunque tales negociaciones no disminuyeron el clima de tensión. Partidarios y detractores de la ENU se enfrentaban en las calles. La oposición parece haber sido fuerte en algunas zonas del sur, como Biobío, Punta Arenas, Curicó y Osorno, por citar algunas. En algunas ciudades se plegaron a los paros y tomas los alumnos de séptimo y octavo básico ${ }^{103}$.

En Santiago, partidarios y opositores a la ENU organizaron distintas manifestaciones. Los estudiantes "democráticos", como los calificaba la prensa opositora, se habían declarado en paro y se reunieron frente a la Biblioteca Nacional, pidiendo la derogación del decreto de democratización de la enseñanza, considerado una maniobra que se encaminaba a iniciar la aplicación de la ENU. El Mercurio y Tribuna dieron amplia cobertura a la manifestación. Este último diario registró el tenor de los cánticos, que ya mostraban un ambiente de fuerte hostilidad hacia el Gobierno: "Allende, escucha, la ENU se va a la ..."; "Queremos ver a Tapia, colgando de un farol, con media lengua afuera, pidiéndonos perdón"; "La ENU y la Patria Nueva, que se las metan en la cueva". Tras la concentración en la Alameda, donde habló Miguel Salazar, marcharon por las calles céntricas y fueron dispersados por la policía. Por su parte, los estudiantes partidarios de la Unidad Popular, encabezados por Camilo Escalona, se reunieron en el Teatro Caupolicán, quizás para prevenir disturbios, ya que algunos diarios afirmaron que no se había permitido el ingreso de los estudiantes del FER (MIR). En el Caupolicán no solo estuvieron los secundarios de la FESES, sino que también destacaron los de liceos industriales, técnicos y comerciales. Al finalizar el acto, que fue cubierto en detalle por El Siglo, marcharon por las calles en dirección a La Moneda, en donde Allende les habló improvisadamente desde el balcón. En la tarde se desataron incidentes más graves, aunque al parecer en ellos ya no predominaban los estudiantes ${ }^{104}$.

100 "Secundarios del país se reunieron con Ministro Tapia", en El Siglo, 11 de abril de 1973, 14.

101 Osvaldo Artaza, cit

102 “Estos son cabros choros!” y “Tapa a Tapia y a la ENU”, en Tribuna, 18 de abril de 1973, 1 y 20.

103 Abundantes noticias en El Mercurio, 25-27 de abril de 1973.

104 El Mercurio, 27 de abril de 1973, 1, 16, 26 y 28; Tribuna, 27 de abril de 1973, 1, 6 y 7; El Siglo, 27 de abril de 1973, 1 y 3 . 
El llamado de la FESES de Salazar fue a regresar a clases al día siguiente ${ }^{105}$. Sin embargo, el viernes 27 de abril continuaron las manifestaciones, las que recrudecieron en violencia, aunque no parece haber sido gravitante la presencia de escolares. Dependiendo de la orientación política, la prensa responsabilizó a unos y otros de los incidentes. Los resultados fueron trágicos, ya que un obrero comunista falleció en una de las manifestaciones, frente a la sede de la $\mathrm{DC}^{106}$. Ese mismo día fue incendiado un trolley en Providencia, cerca de Pedro de Valdivia, hecho en el que participaron liceanos. Así lo recuerda Irma, una testigo:

\footnotetext{
"eran como diez cabros, con uniforme de colegio, y hasta había unos que llevaban sus cuadernos en la mano [...] Esos cabros eran algunos bien chicos; no tendrían más de 10 ó 12 años; claro que había otros mayores, de 18 más o menos, pero llevaban inmensos palos, otros fierros, y había uno que hasta dentro del cuaderno andaba trayendo una cosa grande, cuadrada, como un cuchillo con doble filo y mango de madera"107.
}

A pesar de estos incidentes, la participación de los secundarios ya no tenía la masividad de antes. En varios de estos enfrentamientos, el protagonismo comenzaba a descansar en los grupos de choque, mucho mejor organizados. Por entonces, El Mercurio mostró su preocupación por este "adormecimiento" de la comunidad escolar frente a los propósitos "totalitarios" del Gobierno. El nuevo ministro, Jorge Tapia, estaba siendo eficaz en atenuar las críticas, por lo que el diario opositor concluyó: "nada sería más peligroso que creer que el oficialismo abandonó sus propósitos de controlar políticamente la enseñanza chilena" ${ }^{108}$.

\section{REACTIVACIÓN DE LA LUCHA CONTRA EL GOBIERNO}

Pero el agotamiento de la movilización en torno a la reforma educacional provocó su sustitución por otro tema: el conflicto entre el Gobierno y los mineros del cobre. Pronto la FESES manifestó su solidaridad con los trabajadores, y el 24 de mayo se sumó a las manifestaciones callejeras, junto a los universitarios ${ }^{109}$. En los incidentes que estallaron a raíz de la marcha de los mineros de El Teniente, nuevamente se hicieron presente los estudiantes secundarios. En los días previos a su llegada a Santiago, la directiva completa de la FESES fue detenida, a raíz de enfrentamientos con la policía, lo que dio pie a que el clima se hiciera aún más tenso el 15 de junio, cuando se produjeron los incidentes más graves. Grupos de secundarios y universita-

105 "DC de enseñanza media ordenó vuelta a clases", en El Siglo, 27 de abril de 1973, 9.

106 Al respecto se inició una larga investigación para determinar si José Ricardo Ahumada había sido asesinado por una bala proveniente del edificio donde estaban las oficinas de la DC o de la misma marcha. El Mercurio, 28 de abril de 1973, 1 y 12.

107 Guillermo Tejeda, "Yo venía en el troley que incendiaron", en Ramona 80, Santiago, 8 de mayo de 1973, 20-21.

108 “Adormecimiento a la Comunidad Escolar" (edit.), en El Mercurio, 21 de mayo de 1973, 23.

109 "Apoyo a mineros.- Huelga de estudiantes secundarios y de la Universidad de Chile", en El Mercurio, 24 de mayo de 1973, 17. 
rios opositores participaron en los hechos de violencia en el centro de Santiago, junto a grupos de choque organizados, mientras otros manifestaban su apoyo al Gobierno frente a La Moneda. En el acto central de apoyo a los mineros, realizado el 19 de junio en Avenida Bulnes, hablaron los dirigentes de los gremios movilizados: Miguel Salazar por la FESES, Guillermo Medina por los mineros y Eugenio Retamal por los trabajadores de televisión de la Universidad de Chile ${ }^{110}$.

Tras el Tanquetazo del viernes 29 de junio, varios liceos volvieron a convulsionarse a raíz de las tomas promovidas por el MIR y algunos sectores de la Unidad Popular. La consigna era transformar los establecimientos escolares en trincheras contra un posible nuevo golpe, lo que fue una réplica a nivel escolar de las tomas de fábricas que proliferaron por entonces. Grupos de estudiantes ocuparon liceos de varias comunas: en el perímetro central (Liceo 5 de Niñas de calle Portugal, Aplicación y 8 de Hombres), en Nuñoa (7 de Hombres y Manuel de Salas) y en barrios periféricos (Liceo 13 de La Granja, en el paradero 19 de Santa Rosa; y el Mixto 17 de La Pintana, en el paradero 47 de Santa Rosa). Algunos que estaban en toma por parte de la oposición desde antes (como el Liceo 11 de Niñas, en Macul) fueron atacados ${ }^{111}$.

La FESES de Salazar adoptó una postura oficial de cautela frente a la amenaza de golpe. Afirmó que estaba dispuesta a defender el régimen constitucional con "actuaciones concretas", pero que esto no significaba una excusa para adoptar acciones irresponsables. Rechazó la toma de colegios e hizo un llamado a no dejarse llevar por grupos aventureros.

\begin{abstract}
"Por nuestra parte, hemos hecho que los estudiantes secundarios permanezcan en clases, aun cuando hay motivos de sobra para salir a las calles a luchar por nuestras reivindicaciones gremiales, pero estamos conscientes que hoy día se está jugando algo muy importante por Chile, pero desgraciadamente hay elementos inconscientes que buscan otros propósitos con la toma de los colegios secundarios"112.
\end{abstract}

En la fase final de la Unidad Popular, se inició una nueva oleada de paros gremiales (que nuevamente incluyeron al poderoso gremio de los transportistas, además del comercio y los médicos). Los profesores particulares, agrupados en la FETEP, fueron una de las organizaciones que se plegaron al paro indefinido. Artaza, a nombre de los estudiantes particulares, anunció la adhesión de la Confederación (CODEPART) y señaló: "ha llegado la hora de la decisión de dejar la sala para salir a la calle a defender la libertad de educarse, el derecho a alimentarse y la necesidad de que el Gobierno rectifique o se vaya". Informó a la prensa que muchos profesores y estudiantes fiscales se estaban plegando al paro, sobrepasando a las directivas de sus organizaciones ${ }^{113}$.

110 Véanse las noticias en El Mercurio, 13-20 de junio de 1973; “Qué se fizo el presidente?”, en Qué Pasa 114, 21 de junio de 1973, 6-8.

111 Noticias sobre las tomas en La Prensa, 3 de julio de 1973, 4; 5 de julio de 1973, 9; 6 de julio de 1973, 6 y 9; 9 de julio de 1973, 5 .

112 "FESES rechaza toma de colegios e industrias", en La Prensa, 8 de julio de 1973, 7.

113 "Nuevos sectores en paro", en El Mercurio, 8 de septiembre de 1973, 1 y 12. 
En esta fase, la FESES de Salazar había entrado en una pugna interna entre quienes promovían una postura más radical (la Juventud Nacional y Patria y Libertad) y otra menos confrontacional, aunque no menos opositora (liderada por el propio Salazar). El 9 de septiembre, a días del golpe, en medio de la ola de paros gremiales (que ya incluía al poderoso gremio de los transportistas), Allamand le enrostró a la directiva su "conducta vacilante, titubeante y preferentemente indefinida", y el haber dejado de ser la "vanguardia de la lucha juvenil antimarxista". Por ello, le exigía convocar a un paro total e indefinido y demandar la renuncia de Allende. En caso de no cumplir "con su deber", agregaba Allamand, "nosotros cumpliremos con el nuestro". La amenaza no tardó en hacerse efectiva, ya que ese mismo día un grupo de 500 alumnos se tomó el Liceo de Aplicación, exigiendo un cambio de actitud en la FESES. Al día siguiente hubo escaramuzas con un grupo de izquierda que intentó recuperar el local. Miguel Salazar se hizo presente y logró el desalojo, bajo la promesa de que la FESES que dirigía ya había acordado un paro para el día $12^{114}$.

\section{REFLEXIONES FINALES}

En este artículo hemos puesto mayor atención a los aspectos organizacionales y a las disputas políticas dentro de la FESES, durante los convulsionados años de la Unidad Popular. No obstante la magnitud de sus movilizaciones, su reconstrucción histórica había sido poco considerada por los investigadores de este período.

A pesar del aporte que se pueda hacer en este campo a partir de estos estudios exploratorios, no debe pensarse que la historia de estas organizaciones se agota en estas dimensiones. Varios aspectos fueron surgiendo en el curso de esta investigación, y en estas líneas finales quisiéramos referirnos a las proyecciones de un tema como este.

Por ejemplo, resulta necesario reconocer que el movimiento estudiantil secundario estaba conformado internamente por redes políticas y sociales, y no solo por estructuras organizacionales formales. Sus liderazgos internos y las historias personales de sus miembros ayudaron a crear distintos niveles de integración, conflicto y vivencias comunes, donde el componente espacial era importante.

Los estudiantes secundarios, de acuerdo a la composición social y la ubicación de los liceos, conformaron verdaderas redes de articulación. Silvia, del Liceo 2 ubicado en Matucana, nunca llegó a conocer a alguien del Liceo Lastarria, enquistado en una comuna no solo físicamente lejana, sino también distante socialmente, en un barrio impenetrable. En cambio, entre los liceos 1, 2 y 3 de Niñas, el Amunátegui y el Cervantes, todos ubicados en el perímetro central de la ciudad de Santiago, había mayores vínculos. Aun así, dentro de ese círculo las afinidades estaban acotadas: en el caso de los liceos de niñas, había una diferencia entre el 2,

114 "Piden cambio en posición de FESES", en El Mercurio, 10 de septiembre de 1973, 32; "Incidentes estudiantiles en el Liceo de Aplicación”, en El Mercurio, 11 de septiembre de 1973, 20. 
más “proletario", y los más exclusivos 1 y $3^{115}$. Probablemente, en estas percepciones había un buen componente de prejuicio social, pero en la práctica resultaban muy decisivas en la forma en que se interactuaba política y socialmente. Algo similar ocurría entre los liceos de San Miguel o los del barrio alto (Lastarria, el Liceo 11 de Hombres y el 7 de Providencia), pero ninguna segmentación social y espacial generaba redes claras y nítidas comunes a todos, porque, en ocasiones, determinadas afinidades políticas podían significar -en algunos estudiantes- acceder a un mundo distante e impenetrable para otros.

La participación de los estudiantes secundarios siguió diversos caminos durante los convulsionados años de la Unidad Popular. Aquí nos hemos detenido en las movilizaciones estudiantiles lideradas por las principales orgánicas de la época, pero lejos de predominar formas racionalizadas de demandas gremiales y políticas, en el espíritu del momento hubo un ambiente de protesta y descontento y una oleada de participación que llevó a que las reivindicaciones tomaran cauces insospechados.

Entre la amenaza de la inminente dictadura marxista y la necesidad de aportar al triunfo de la revolución -finalidades que convocaban a un segmento del estudiantado-, había también espacio para un abanico amplio de posibilidades, donde tenían cabida expectativas mucho más concretas y palpables, como la solución de problemas curriculares, organizacionales (participación, nombramiento de autoridades) y de mejoramiento en las condiciones materiales de los liceos (desde compra de mobiliario hasta cambio de local). Todas ellas fueron demandas válidas por las que luchar, a los ojos de sus protagonistas.

Los componentes político y gremial de las demandas estudiantiles estaban estrechamente integrados. Esto ocurría también en otros segmentos sociales, como los trabajadores. De hecho, una de las formas más efectivas que tuvo la oposición para alcanzar altos niveles de movilización social fue canalizar las demandas sectoriales que comenzaron a surgir.

Aunque las organizaciones estudiantiles cumplieron este papel, detrás de ellas parece haber existido un mundo bastante más complejo, multifacético, dinámico y contradictorio. Esto no se refleja en las declaraciones y comunicados de prensa, sino en los testimonios de los protagonistas anónimos. Las federaciones de colegios particulares, por ejemplo, agrupaban tanto a colegios pagados como gratuitos. Sin embargo, la conducción estaba en manos de los primeros, como lo evidencia el origen de los dirigentes. Entre los estudiantes de colegios particulares, tanto pagados como subvencionados, hubo expresiones de apoyo al Gobierno, pero el entusiasmo inicial por la experiencia de la Unidad Popular, que logró contagiar a importantes sectores de la cultura católica, rápidamente comenzó a diluirse y estos sectores se alinearon con igual fervor en la oposición ${ }^{116}$. Tardíamente, algunos sectores de izquierda intentaron recuperar posiciones en los colegios privados ${ }^{117}$.

115 Silvia Fernández, cit.

116 Osvaldo Artaza, cit.

117 En 1973, por ejemplo, se mencionó la existencia de una Federación de Izquierda de Estudiantes Particulares, entre cuyos dirigentes se encontraba Gonzalo Martínez. "Impresionante acto estudiantil en el Caupolicán. Escalona: los estudiantes estamos junto al Gobierno y a los trabajadores", en El Siglo, 27 de abril de 1973. 
Otro elemento que queda encubierto por la vocería oficial de las movilizaciones es la relación existente entre los distintos grupos etarios. Si nos basamos en los registros escritos, es claro el predominio de los jóvenes de los cursos superiores, pero no son pocas las ocasiones en que podemos apreciar, de modo indirecto, que los muchachos más pequeños, digamos de 12 o 13 años, también se hacían presente en las organizaciones y sobre todo en las múltiples formas de participación callejera. Generalmente, esto producía preocupación en los sectores que se sentían afectados, tanto de derecha como de izquierda. Fuera por la amenaza de manipulación o por otros peligros, se tendía a criticar este tipo de participación.

Aunque los dirigentes que encabezaban las federaciones de estudiantes secundarios generalmente tenían entre 16 y 18 años de edad (excepcionalmente mayores, sobre todo en los cargos superiores ${ }^{118}$ ), el movimiento mismo integraba a muchachos de edades más bajas. Los dirigentes estudiantiles generalmente habían iniciado su militancia política entre los 13 y 14 años: Camilo Escalona a los 13, al igual que Guillermo Yunge y Augusto Samaniego; Ricardo Solari a los 15; aunque de una generación anterior, Gutenberg Martínez a los $14^{119}$.

En todo caso, la participación de los estudiantes de menor edad estaba supeditada al protagonismo de los mayores. En las convenciones que se organizaron regularmente hasta 1969, los liceos que tenían cursos básicos (antes denominados "preparatorias") tenían delegados "oficiales" de enseñanza media y "fraternales" de enseñanza básica, estos últimos sin derecho a voto ${ }^{120}$.

Cuando se relatan las movilizaciones sociales de la época de la Unidad Popular, queda la sensación de un universo impregnado por el componente político. Si comparamos con otros momentos de la historia, efectivamente este factor tuvo mucho mayor presencia y logró impregnar de un modo muy intenso la vida de las personas, pero no al grado de ahogar otros componentes de la vida personal.

En la novela Los últimos días de la historia (2001), de Roberto Brodsky, se enfatiza esta mirada, probablemente mucho más realista, donde las escaramuzas de

118 Algunas de esas notables excepciones: Rigoberto Quezada, dirigente socialista, tenía 20 años cuando postuló a la presidencia de la FESES a fines de 1971. A los 19 años adquirió notoriedad al caer detenido, a fines de mayo, en el campamento paramilitar de Chaihuín, cerca de Valdivia, organizado por los grupos guevaristas dentro del Partido Socialista. Por entonces, era dirigente de los secundarios y alumno de IV Medio del Liceo 9 de El Llano (San Miguel). Sobre su participación en los sucesos de Chaihuín, véase el artículo de Cristóbal Peña, "La misteriosa desaparición de un ex cadete naval en un campo guerrillero a meses de la elección de Allende", en sitio web de CIPER, Centro de Investigación e información Periodística, http://ciperchile.cl/. Entre los dirigentes comunistas estaba el caso de Álvaro Alarcón, que alcanzó celebridad a mediados de 1969, cuando una bomba lacrimógena le partió el cráneo en una de las manifestaciones en contra de la visita de Rockefeller. Fue presidente del Centro de Alumnos del Liceo 12, así como presidente de la FESES. Varias veces se le canceló la matrícula, al parecer por sus actividades. El Siglo, 4 de octubre de 1971, 5. Milton Lee, el dirigente del MIR, postuló a la presidencia de la FESES cuando tenía 21 años. En enero de 1972 tenía 20 años. Mayoría 15, 26 de enero de 1972, 19.

119 Las edades son aproximadas y se basan en datos personales entregados en diversas entrevistas e información biográfica de origen periodístico.

120 Así lo relató el dirigente Patricio Paniagua, por entonces secretario general de la FESES, para el caso del Liceo Amunátegui, el que tenía derecho a ocho delegados oficiales y dos fraternales. La información la entregó con ocasión del quiebre en la Convención de 1969. "Categórico desmentido...", op . cit. 
Patria y Libertad, las “colas” y la polarización política están presentes, pero también el despertar sexual del joven protagonista, sus dilemas familiares y sus juegos adolescentes, aspectos que probablemente para él tenían mucho más relevancia. Algo similar, aunque con menor énfasis, se aprecia en la cinta Machuca (2004), de Andrés Wood (donde el propio Brodsky colaboró como guionista). Aunque la experiencia escolar en el Colegio Saint George -con todo el dramatismo que provocó la polarización política- marca la vida de los protagonistas, también hay espacio para la risa, el enamoramiento y los juegos.

Cuando vemos el caso de los muchachos que vivieron de un modo más intenso el compromiso militante, podremos notar que incluso ellos, los que debían estar menos expuestos a la cultura "burguesa" circundante, convivían con modelos de socialización que el discurso ideológico más cerrado consideraba formas típicas de alienación. Para graficar este aparente contraste, Alejandro recuerda, como muchos miristas jóvenes de esos años, que una tarde de sábado, en un ampliado de dirigentes secundarios del MIR, memorable por la asistencia de Miguel Enríquez y otras celebridades, se suspendió la larga e intensa jornada de trabajo político para que los muchachos pudieran ver "Música Libre"121.

Aunque aquí hemos ensayado una reconstrucción histórica de la FESES en sus pormenores orgánicos e institucionales y en su vinculación con el contexto político nacional, otros componentes de su vida interna, incluyendo estas vivencias cotidianas, deberían ser incorporados para desentrañar, de mejor modo, su complejo papel en aquellos años.

121 Testimonio de Alejandro Núñez al autor, 15 de febrero de 2008. 
